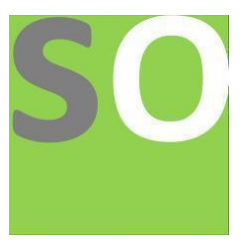

Article title: Protection and Monitoring of DESO

Authors: Reza Jalilzadeh Hamidi[1]

Affiliations: ECE Department, Georgia Southern university[1]

Orcid ids: 0000-0001-9395-4169[1]

Contact e-mail: reza.j.hamidi@gmail.com

License information: This work has been published open access under Creative Commons Attribution License http://creativecommons.org/licenses/by/4.0/, which permits unrestricted use, distribution, and reproduction in any medium, provided the original work is properly cited. Conditions, terms of use and publishing policy can be found at https://www.scienceopen.com/.

Preprint statement: This article is a preprint and has not been peer-reviewed, under consideration and submitted to ScienceOpen Preprints for open peer review.

DOI: 10.14293/S2199-1006.1.SOR-.PPZ3SSM.v1

Preprint first posted online: 26 January 2022

Keywords: Autonomous Grid, Fault Current, Fault Level, Fault Response, IBR, Inverter, Source-Independent Protection 


\title{
Protection and Monitoring of DESO
}

\author{
Reza Jalilzadeh Hamidi \\ Ananta Bijoy Bhadra
}

\section{Georgia Southern University, ECE Department, 30458 GA, USA. rhamidi@georgiasouthern.edu ananta.bijoy@ieee.org}

\section{Nomenclature:}

DER: Distributed Energy Resource

Al: Artificial Intelligence

ANN: Artificial Neural Network

CSI: Current Source Inverter

DES: Digital Energy System

DG: Distributed Generation

ES: Expert System

ESS: Energy Storage System

FCL: Fault Current Limiter

FIA: Fault Inception Angle

GA: Genetic algorithm

IBR: Inverter-Based Resource

IED: Intelligent Electronic Device

LVRT: Low Voltage Ride-Through

OC: Over Current

OCR: Overcurrent Relay

PDC: PMU Data Collector

PMU: Phasor measurement unit

PWAM: Protective Wide-Area Monitoring

SCADA: Supervisory Control and Data Acquisition

SMT: Synchronized Measurement Technology

SVM: Support Vector Machine

TCC: Time Current Characteristics

TL: Transmission Line

TW: Traveling Wave

VSI: Voltage Source Inverter

WAM: Wide Area Monitoring

WLS: Weighted Least Square 
Abstract - This chapter first accurately reviews the basics of smart microgrid protection since the definitions vary from a reference to another. Then it focuses on the fault responses of Inverter-Based Resources (IBR's) as those are emerging technologies that will be playing the great role of interfacing primary energy resources and the grid. In particular, for materialization of net-zero Carbon emission in electricity generation, the use of IBR's is indispensable. However, the non-universal and software-defined IBR fault responses make conventional relays such as overcurrent, directional, and distance relays inapplicable in heavily IBR-based grids. Therefore, the discrepancy between conventional and IBR fault responses is elaborated and possible solutions to the looming protection issues are discussed. The shortcomings and merits of each solution are also discussed.

Key Words - Autonomous Grid, Fault Current, Fault Level, Fault Response, IBR, Inverter, Source-Independent Protection

\section{Introduction}

Digital energy systems are technologies and schemes that utilize digital computers together with digital models to manage the increasingly sophisticated modern energy systems. The emergence of DES will have profound impression on the betterment of energy resiliency, cost-effectiveness, transparency, quality of service, and consequently both customer and provider satisfaction [1] and [2]. One of the major aims of DES's is to develop highly sophisticated and complex protection and monitoring schemes for responding to the smart microgrid needs utilizing communications, uncertainty analysis, and intelligent management capabilities [3] and [4].

The addition of DER's either uncertain renewable-based or dispatchable [5], integration of ESS's, the emergence of new types of power electronic-based loads, adaptive power network topology, DC grids, and so on, necessitates the development of new methods for recognition of faults and protection coordination [6], [7], [8], and [9]. These developments are necessary to safeguard the power grid against new phenomena, new components [9], [10], [11] as well as providing real-time monitoring.

This chapter will provide an insight into the protection and monitoring needs of advanced power grids, and then delivers some of the most up-to-date developments in response to the arising issues and needs.

\section{Overview of Protection Key Points and Definitions}

This section briefly, but precisely, reviews the basics of protection. This is necessary since there are some discrepancies in different resources and technical texts. Therefore, providing a precise definition of the fundamentals will prevent the readers from misunderstandings.

- Protection Zone: with reference to Fig. 1(a), protection zone is a part of a power grid that is protected by a certain protective scheme. Whenever a fault happens in a specific zone, only the faulty zone will be disconnected by the circuit breakers surrounding that zone, and the rest of the system keeps functioning. Conversely, the protective devices supporting a particular zone stay restrained in case of faults outside their own zone.

- Unit protection: following this scheme, the protective relays operate in case of abnormal conditions inside the protection zone, while the relays stay stable for abnormal conditions outside the zone. The circumference of the zone is limited by the measuring devices connected to the relays. For example, and with reference to Fig. 1(a), a unit protection which is differential protection protects a transformer and the zone is the span between two CT's. It 
is worth noting that the $\mathrm{CB}^{\prime}$ s are generally placed in a way that their failure is detected by the closest $\mathrm{CT}$ to them or, in other words, $\mathrm{CB}^{\prime}$ 's are placed toward the protected component. Therefore, $\mathrm{CB}^{\prime}$ s are normally placed inside the protection zone. In Fig. 1(a), the differential relay should react to $F 2$ that is inside the zone, but it should remain restrained against $F 1$ that falls outside the zone. In unit protection, coordination between relays is not needed.
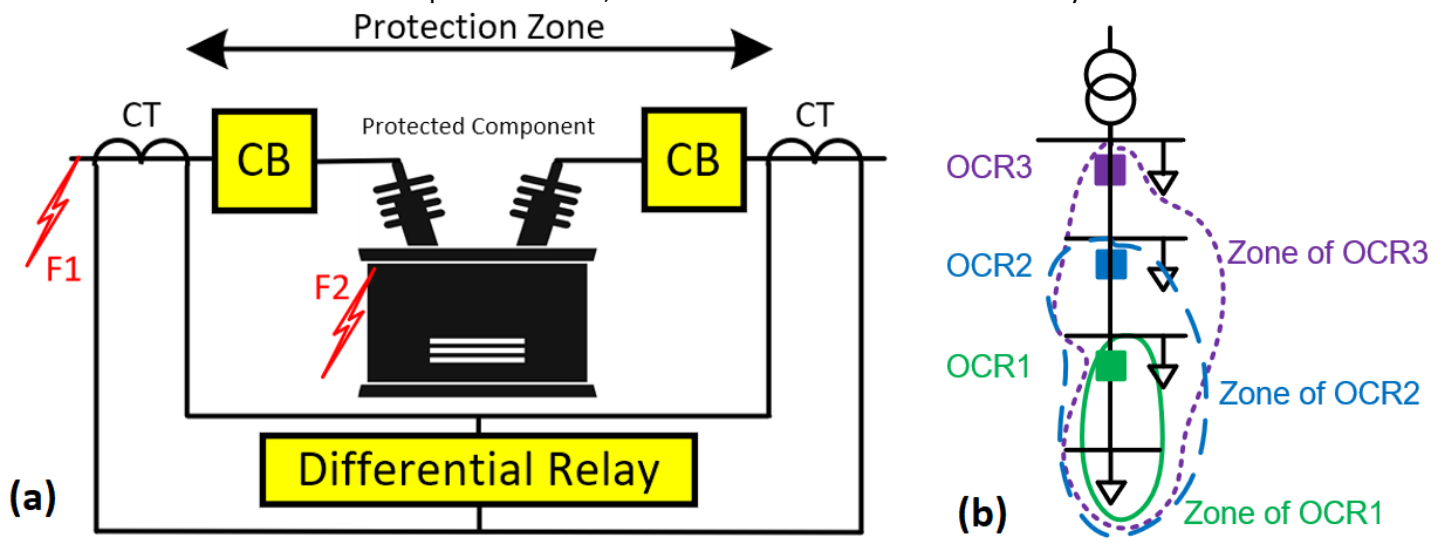

Fig. 1(a). A typical unit protection. (b) A typical non-unit protection.

Non-unit protection: converse to the unit protection, non-unit relays protection zones extend well beyond their measuring components and often cover large portions of power grids. One of the typical examples in this area is OCR's. As shown in Fig. 1(b), each upper OCR overlaps the zones of the lower ones. In non-unit protection, relay-to-relay coordination should be done with extra care following the general protection scheme selected for the grid. - Overlapping Zones: with reference to Fig. 1(b), when some protection zones intersect, the intersection is an overlapping zone. This can be deliberately done for providing backup protection, or it happens unintentionally that often leads to coordination issues.

- Graded coordination: when relays' zones overlap, the closest relay to the fault should react first as the "main" relay to keep the de-energization of the grid as minimal as possible. If it fails to disconnect the faulty zone for any reasons, then the "backup" one should now react. Therefore, non-unit relays are coordinated as the main and backup one(s). This coordination procedure is done by putting the characteristic curves of the backup ones above the main one. For example, as for OCR's, grading can be done considering both time and current which is called time-current-graded coordination, as shown in Fig 2(a). The coordination can be done with respect to time only that is called time-graded coordination, as depicted in Fig. 2(b), or as Fig. 2(c) shows, the coordination can be current-graded (e.g., instantaneous function) [7] and [12].
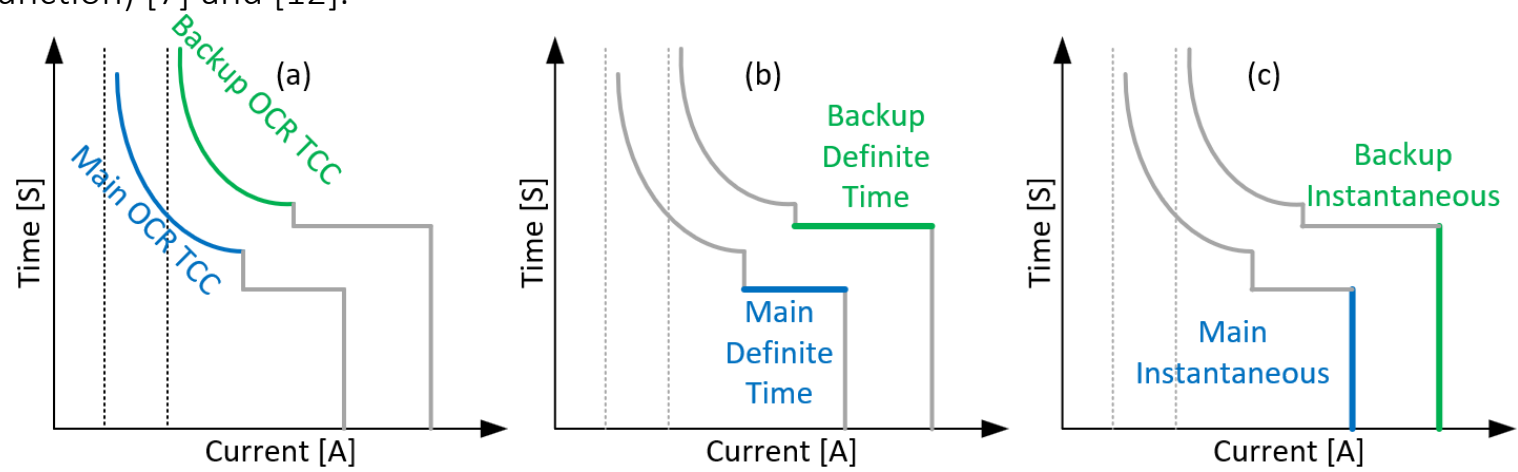

Fig. 2. Different ways for graded coordination. (a), time-current-graded coordination; (b), time-graded coordination; (c), current-graded coordination. 


\section{Overview of Micro Grid Protection Bottlenecks}

\section{1. Loss of Coordination}

- As DER's participate in fault currents and increase their levels, DER's disturb the timecurrent and current graded coordination of non-unit protective devices. However, this has no effect on time-graded coordination.

Solutions: i) Re-coordination of time-current- or current-graded coordination schemes [13]. ii) Using only time-graded coordination [14]. iii) Addition of FCL's to the system [15].

- The second problem arising from DER's is that they change the power flow in distribution grids which conventionally flows upstream to downstream. However, when DER's are added toward the end of feeders, then power-flow direction can be reversed downstream to upstream.

Solution: i) Adaptively readjustments of the settings of OCR's. ii) Addition of directional elements to OCR's to prevent the OCR's from tripping in case of upstream faults.

\section{2. Protection Under-reaching, Desensitization, or Blinding}

With respect to Fig. $\mathrm{C}$, when infeed DER's are added to the grid, the responsible relays sense a fault current lower than the actual fault current passing through the faulty feeder. Therefore, the relays may not react in time and the system gets damaged [16] and [17]. In severe cases, the built-up voltage across the fault resistance and the feeder can decrease the contribution of the main grid to the fault causing blindness of the feeder's relay [17].

Solution: The solution to this issue is to add a protective relay at the DG location.

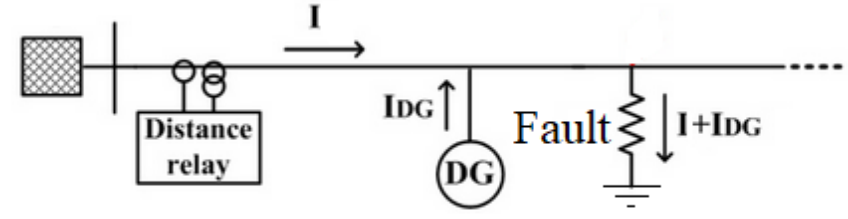

I : Utility current IDG: DG infeed current

Fig. 3. Interconnection of a DG as an infeed.

\section{3. False Tripping (Nuisance and Sympathetic)}

Due to the contribution of DER's to the faults, there are currents flowing throughout the grid during the fault that may cause unwanted tripping of some of the relays in the grid. If a relay reacts to a fault outside its protection zone, it is generally called 'False Tripping' which can be divided into two major categories.

\section{Sympathetic Tripping}

When healthy feeders become disconnected due to a fault in the other feeder, sympathetic tripping happens. For example, in Fig. 4(a), if any of R1 or R2 trips for F1 because of the currents fed by the DG units, a sympathetic trip occurred [18].

Solution: Directional blockers should be added to R1 and R2.

\section{- Nuisance Tripping}

With reference to Fig. 4(b), there are two protection schemes for the faulty feeder with DER's, a) all the DER's should be disconnected (the present-time scheme suggested by [19]). b) Only the fault location should be disconnected, and the rest of the system continues working in the islanding mode (the preferable scheme). If the first scheme is selected for the grid and if $R 2$ disconnects $F 2$ before both $R_{D G 1}$ and $R_{D G 2}$, nuisance tripping will happen. 
Solution: it is suggested that the system is equipped with transfer trip relays that disconnect $\mathrm{R}_{\mathrm{DG} 1}$ or $\mathrm{R}_{\mathrm{DG} 2}$ when R1 or R2 detects a fault [20].

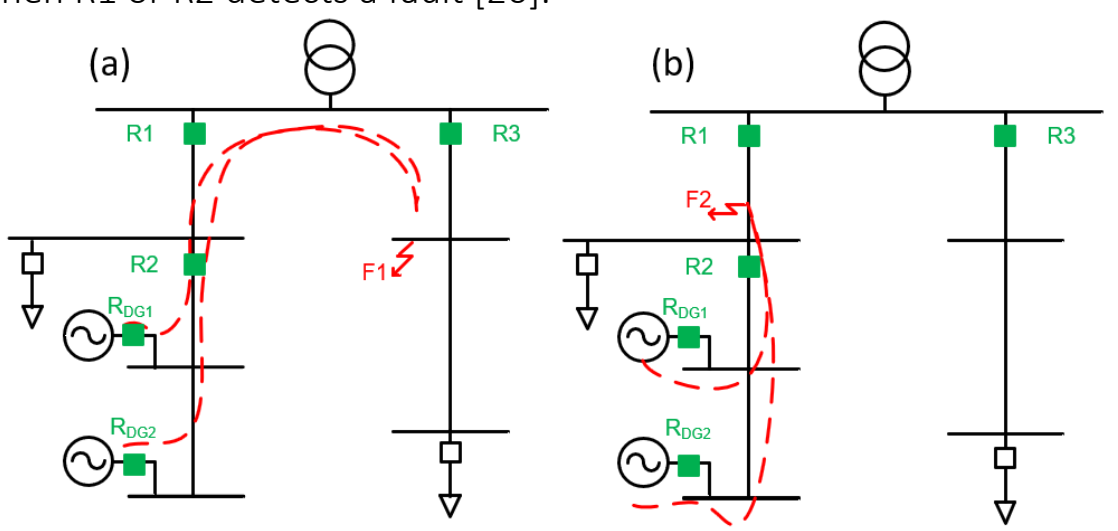

Fig. 4. (a) Sympathetic tripping. (b) Nuisance tripping.

\section{4. Auto-reclosers}

As some faults are temporary (e.g., caused by lightning), the system can be kept from outages with the use of auto-reclosers. A typical operation sequence of auto-reclosers is shown in Fig. 5. However, the number of fast and slow shots, as well as dead times, are selected based on the protection scheme and the grid specifications.

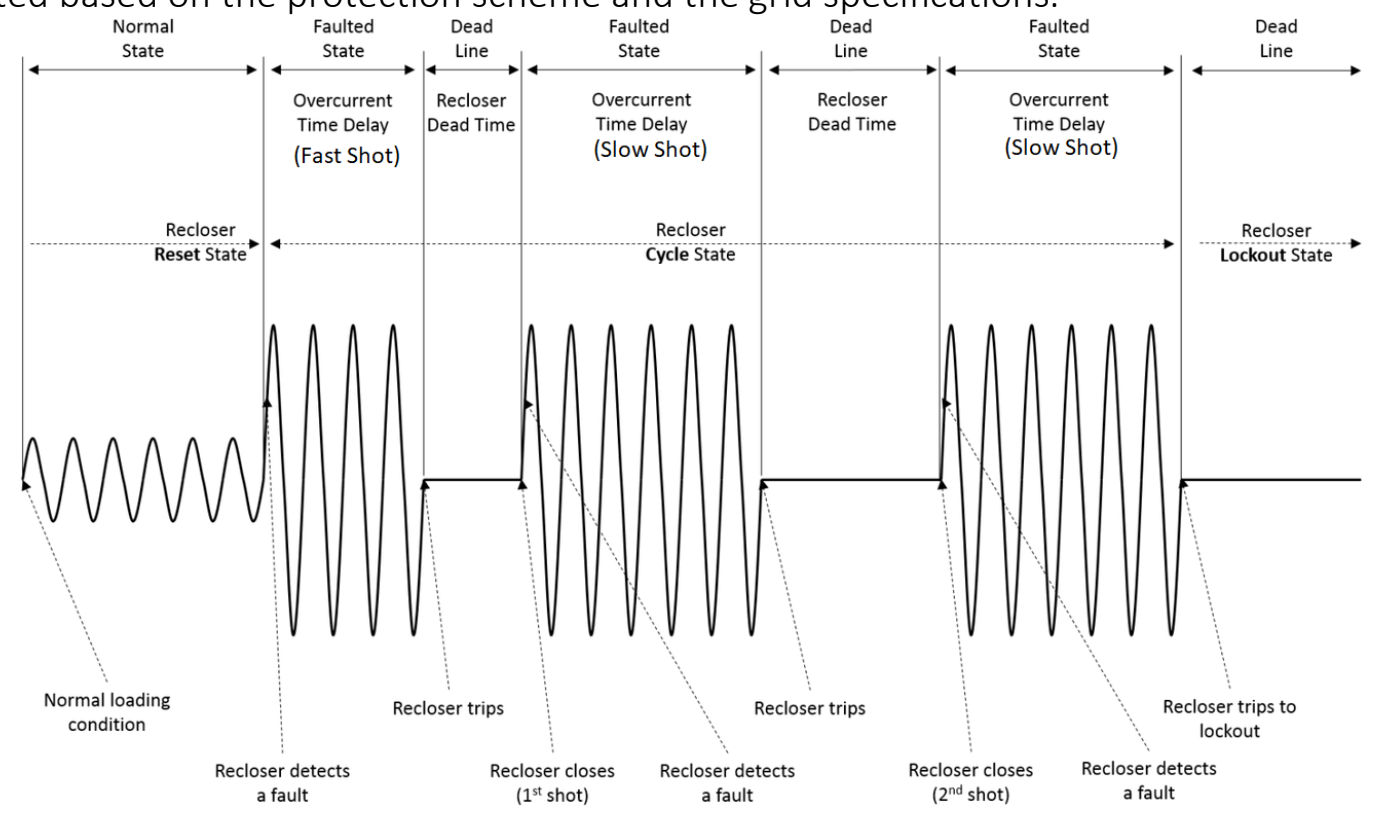

Fig. 5. A typical operation sequence of auto-reclosers.

An auto-recloser is installed in a power grid well upstream and its protection zone covers a large portion of the system as Fig. 6(A) shows. If a temporary fault happens, the recloser deenergizes the system with a short delay as the fast shot in Fig. 5 shows. The dead time should give the arc enough time to quench and when the recloser reconnects after the deadtime, there is no longer any fault in the system. However, if the fault is permanent (e.g., a dropped bare conductor or broken insulator), after several dead shots, the fault still exists and the recloser does not reconnect anymore. In setting the recloser, there are two major schemes to follow as, 
i) fuse blowing scheme in that the recloser gives the fuses enough time to blow and clear the fault during recloser's slow shots. ii) Fuse saving scheme that the recloser does not let fuses blow by having no slow shots.
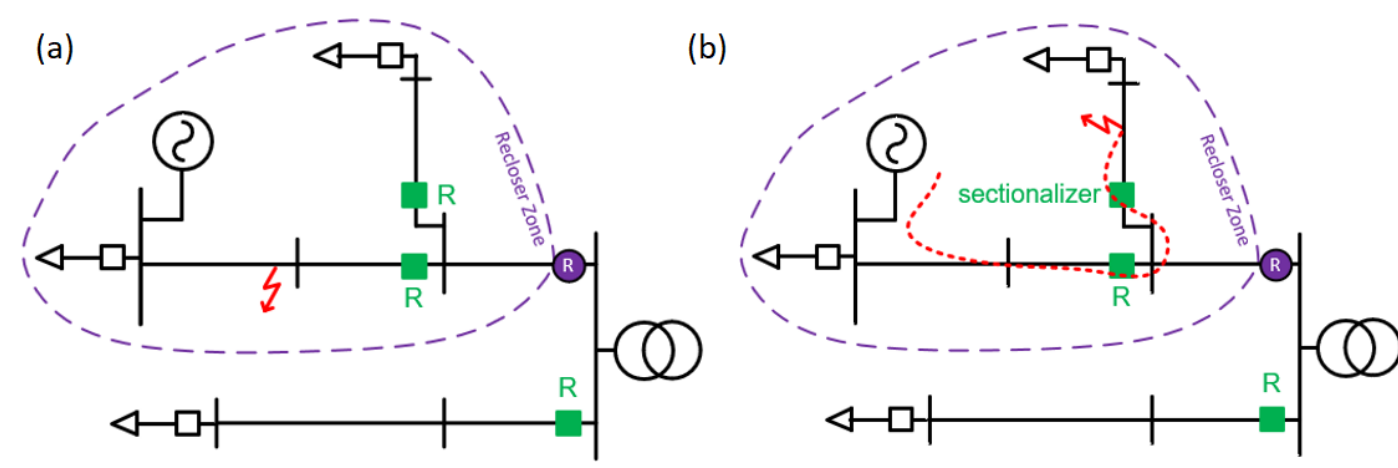

Fig. 6. (a) Auto-recloser protection zone. (b) The sectionalizer issue arising from DER's.

As Fig. 6(b) depicts, when a recloser disconnects a system with DER's connected to it: i) the contribution of the DER to the fault may not let the arc quench. ii) The asynchronous reclosing may result in high currents in the grid.

Solution: for the first issue, the dead time of the recloser should be increased such that the protective systems of all DER's in the recloser zone trip. As for the second issue, a synchronous relay should block asynchronous reclosures.

\section{5. Sectionalizers}

Sectionalizers are devices that are used together with reclosers to disconnect the faulted feeders. When an upper recloser interrupts fault currents, a lower sectionalizer counts high currents (caused by a fault along their feeder) after the dead times. If a specific number of unsuccessful reclosures occurs, the sectionalizer disconnects the faulty feeder during the next dead time.

As Fig. 6(b) shows, the problem arises from the contribution of DER's to the fault that does not allow the sectionalizer to count the high currents and dead times since a fault current continuously flows from the DER without any interruption during the recloser's dead times.

\section{6. Unintentional Islanding}

Different contingencies, especially false tripping, may result in undesirable islanding in that a part of the system stays energized by DER's while it is disconnected from the rest of the power grid. Islanding operation of the grids requires advanced frequency, voltage, loadsharing control systems as well as sophisticated monitoring systems. Therefore, in most of the practical grids, a part of the system should not be allowed to continue working in islanding mode [20]. There is a significant body of research looking into islanding detection. Based on IEEE Standard 1547, DER's must be switched out from the grid in 2 s after the occurrence of islanding [19]. To this end, reliable islanding detection methods are required. Major types of islanding detection methods have been developed as shown in Fig. 7 [21] and [22]. 


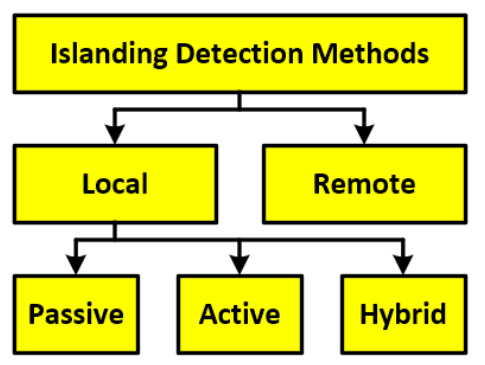

Fig. 7. General classification of islanding detection methods.

i) Remote methods utilize both the local and far measurements through communication systems for detection of islanding.

ii) Local methods only rely on local measurements at the location of the DER's and they do not use communications.

- Passive islanding detection methods rely on measuring electrical parameters of the grid such as voltage displacement, frequency deviation, rate of change of frequency or voltage (ROCOF/ROCOV), rate of change of frequency with respect to power (df/dp), total harmonic distortion together with voltage unbalances. However, large non-detection zones and false tripping are major downsides of passive methods.

- Active methods in that some external signals are injected into the grid. Then, the system response to the signal is observed at the location of DER's and premised on the system response, a probable islanding is detected. However, power quality issues due to the injected signal and also comparatively longer times to detect the islanding detract from active methods.

- Hybrid methods have been developed to improve the shortcomings of passive and active methods. This category not only injects a noise into the system, but it also concurrently monitors the electrical parameters throughout the grid for the betterment of islanding detection.

\section{7. Heavily Power Electronic-Based Grids}

In contrast to conventional power grids which are mainly supplied by synchronous or induction generators. The fault contribution and during-the-fault current patterns of the conventional generators are well-known. However, the contribution of the power-electronicbased sources is unpredictable, software-defined, and incomparable with the conventional generators [20] and [23]. The protection issues caused by IBR's are summarized in Fig. 8 and then, each one is described.

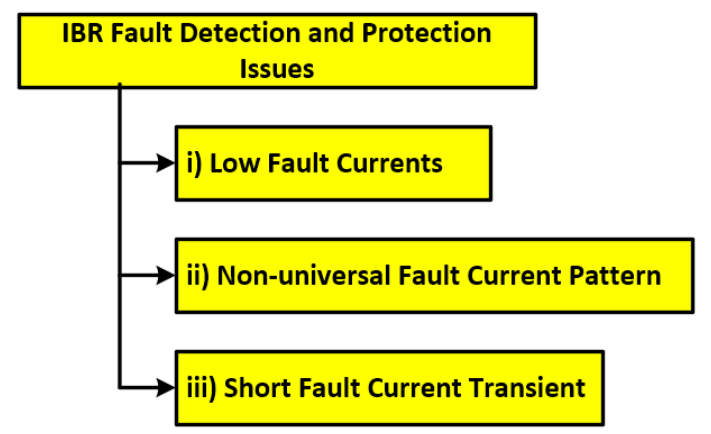

Fig. 8. Main protection issues of IBR's. 
i) In conventional systems, a fault is detected by fault-current features, this is the most basic and widely in use method for detection of faults in power systems. The steady-state fault current is reversely proportional to the driving-point impedance (diagonal elements of the impedance matrix, also referred to as Z-bus) of the fault location. However, in the case of heavily or $100 \%$ inverter-based grids, the size and pattern of fault currents do not follow the above-mentioned well-known patterns [20], [19], [23], and [24]. The differences are as follows,

- Magnitude: IBR's generate fault currents in order of 1.00 to 1.2 p.u. (in less common ones, the fault current can increase to 1.5 p.u.), while conventional generators typically generate fault currents as large as 3 to 5 p.u. [25]. This can be found in Figs. 9 and 10.

- Fault current Phase Angle: In conventional systems fault currents lag voltage. However, in the case of IBR's, the fault currents can be capacitive, inductive, or even resistive [23] and [25].

- Sequence: The negative and zero current sequences are negligible depending on the control system of the IBR, whereas those sequences can be high in case of unsymmetrical faults in conventional systems [19], [23], and [24]. Fig. 9(b) depicts this.

- Fault Current Direction: the directional elements find direction of fault currents by comparing the angle between voltage and current, considering that the system is inductive, and therefore, the fault current lags the voltage. As abovementioned, this may not happen in heavily IBR-dependent systems and directional elements fail in detecting fault-current direction.

ii) Non-universal Fault Current Pattern, non-universal control methods for IBR's make the fault patterns irregular and non-uniform in IBR-based grids which makes the use of some conventional protection schemes impossible for protection of the grids [19] and [23].

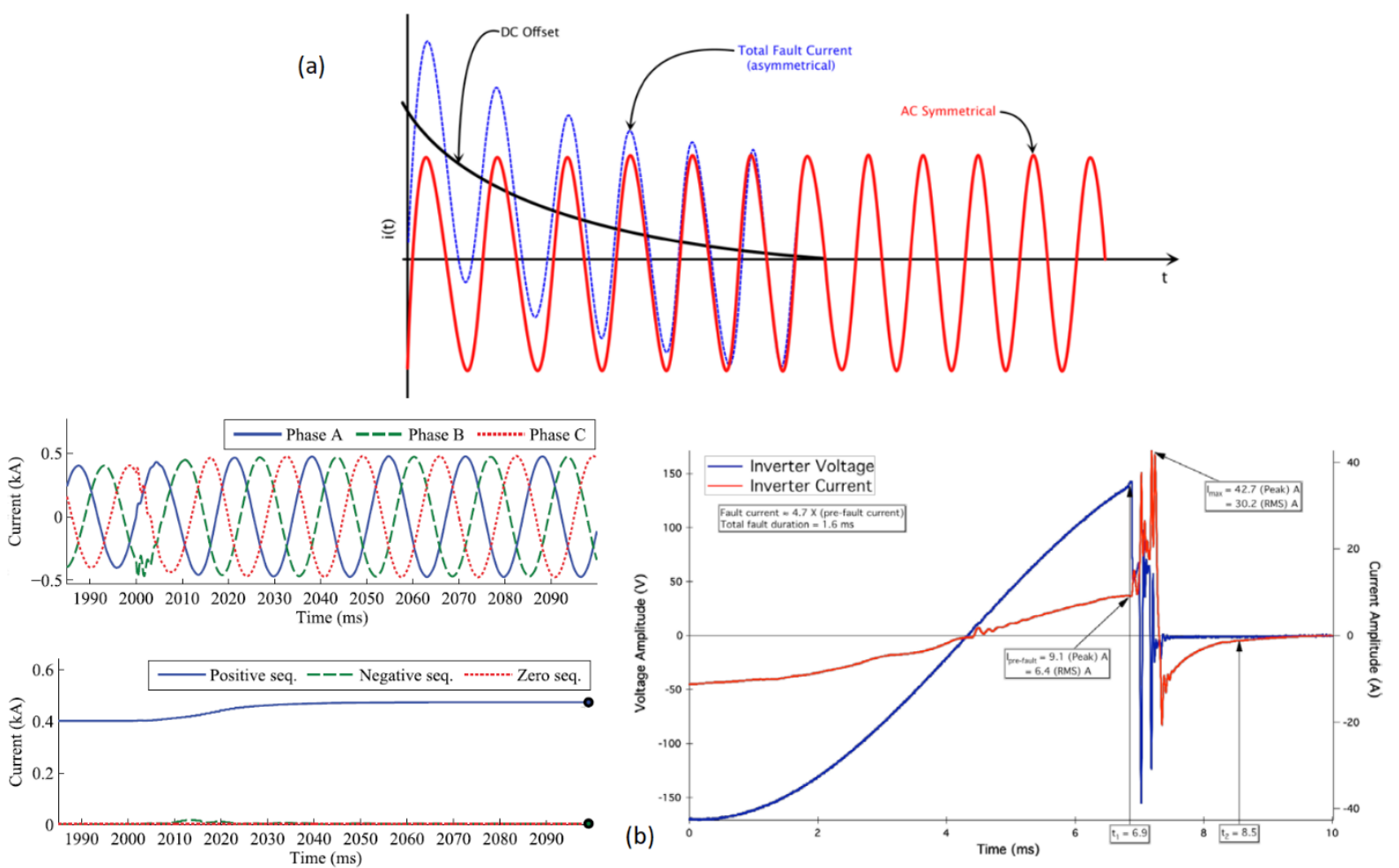

Fig. 9. (a) A typical fault current in conventional systems. (b) Examples of the fault responses of IBR's. The figures are from [25] and [26]. 


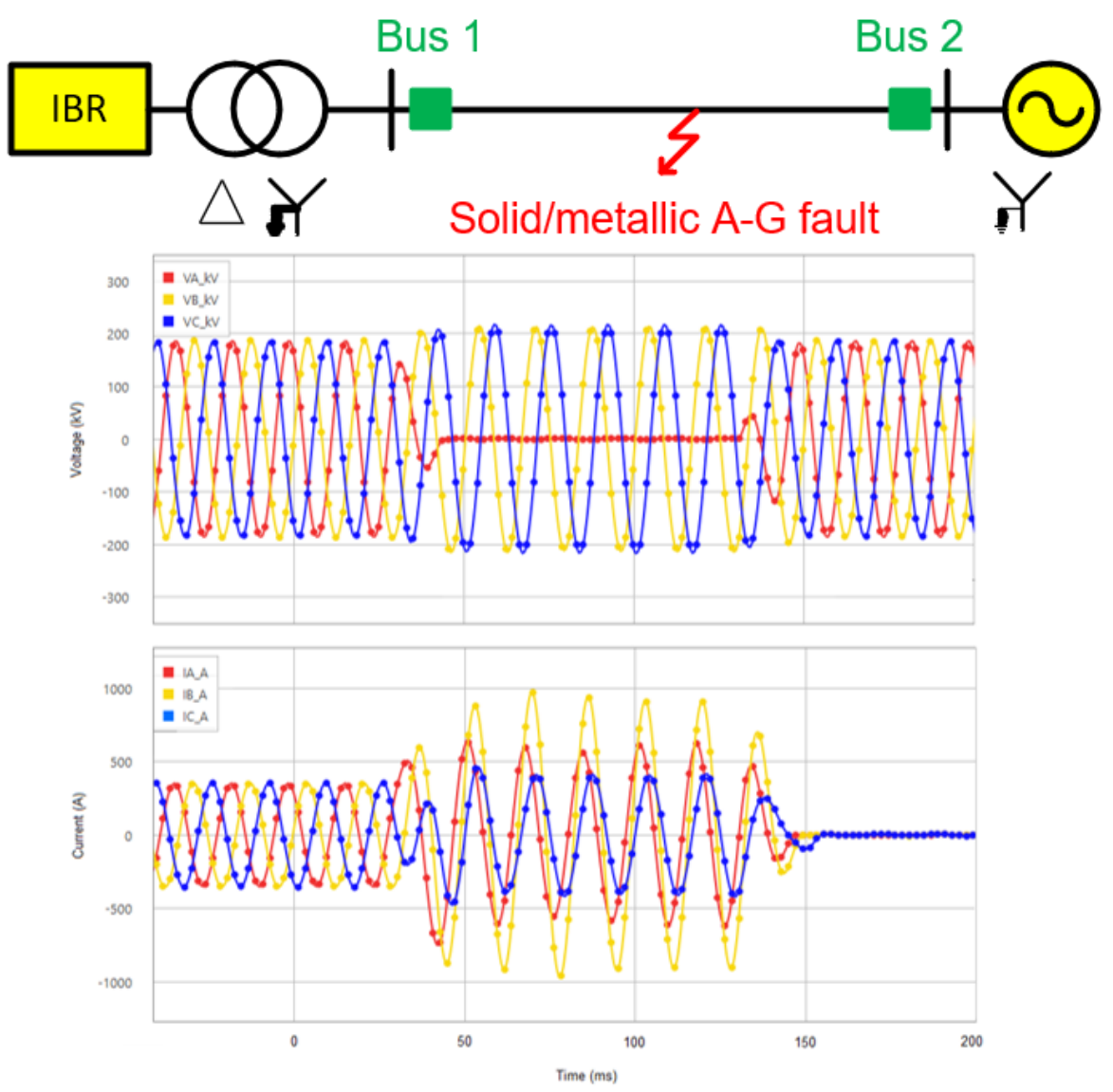

Fig. 10. A system including synchronous generators and IBR's. The AC parts of pre-, during-, and post-fault voltages and currents are shown as well [23].

iii) Short Fault Current Transient, the transient of fault currents in conventional grids is mainly associated with the sub-transient impedance of generators and $\mathrm{X}$-to- $\mathrm{R}$ ratio of the driving point impedance. However, a limited and relatively low amount of energy stored in inverters' DC-bus capacitances leads to a rapid decay in the short-circuit current in converterdominated grids [27] and [28]. Moreover, inverters are rarely controlled to mimic the behavior of generators during a fault.

Accordingly, in IBR-based grids, protection schemes have to mostly rely on voltage, sequential components, or extracting other features from during-fault current or voltage. This will be elaborated in the next sections.

Moreover, Fig. 10 shows the voltages and currents at Bus 1. The fault is bolted A-G. The voltage pattern is analogous to conventional systems. However, during-fault currents are significantly different. It is obvious in Fig. 10 that i) the phase currents are nearly in-phase with one another because of the high zero-sequence current produced by the synchronous generator. ii) The magnitude of B-phase current is the largest although the fault is A-G. iii) Regardless of the inductive nature of the $\mathrm{TL}$, the current and voltage of phases are somehow in phase [23].

Accordingly, protection algorithms trusting the fault-current magnitude, the phase differences between the phase currents, and the phase differences between currents and voltages are no longer reliable in heavily IBR-contaminated grids. Therefore, overcurrent, directional, and distance relays have no use in such grids, yet differential relays are still useful [23]. 


\section{IBR Control Schemes and Grid Protection}

In order to profoundly dig into the arising issues from IBR's, first, their control methods should be reviewed. There are three core control schemes for IBR's summarized in Table I [27].

Table I. General Control Methods of IBR's.

\begin{tabular}{|c|c|c|}
\hline Control Scheme & Control parameters & Inverter Type \\
\hline Grid Forming & VF Control & VSI $^{+}$ \\
\hline Grid Feeding & PQ Control & CSI $^{*}$ \\
\hline Grid Supporting & Droop Control & CSI or VSI \\
\hline \multicolumn{2}{|c|}{ + Voltage Source Inverter, ${ }^{*}$ Current Source Inverter. }
\end{tabular}

In the grid forming scheme (also referred to as voltage-frequency control, V/F control), the inverter actively regulates its output voltage and frequency. Therefore, the inverter has to consciously supply the grid. The V/F-controlled IBR's can be modeled with a controlled voltage source in series with impedance [27] and [29]. The need to control the output power is answered by controlling their output frequency to adjust their bus angle [27]. Fig. 11(b) shows the principal structure and control characteristics of grid-forming inverters. It is noteworthy that at least one grid-forming inverter should be in any autonomous grid.

- Pursuing the grid feeding scheme (or real-and-reactive power control, PQ-control), the inverter tracks the voltage angle and frequency of the system mainly using PLL's and supplies a current to the grid proportional to the reference values for real and reactive powers. These inverters work as CSI and they do not undertake frequency and voltage correction tasks. In today's practical grids, all the inverters must be CSI [30]. If harmonic analysis and internal aspects of inverters are not under question, the equivalent circuit of a PQ-controlled IBR (CSI) can be a power-controlled current source with or even without a parallel impedance [31] as shown in Fig. 11(a). This scheme efficiently controls the power injection to the grid since the inverters are relaxed from controlling the voltage and frequency.

- The grid supporting control scheme combines the droop controller with any of the other two schemes to lessen the immediate demand-supply mismatch. however, the power quality issue is a concern whenever the grid supporting scheme is followed [27] and [32]. Figs. 11(c) and (d) respectively show grid-supporting CSI and VSI basic structures and droop curves.

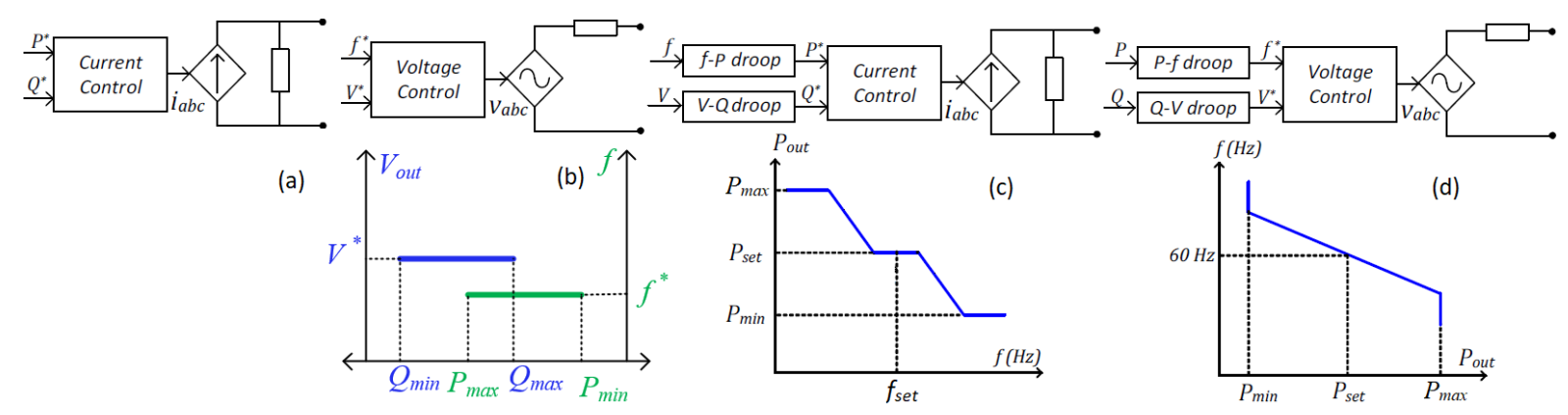

Fig. 11. Summarized general controllers and their characteristics. (a) Grid feeding. (b) Grid forming and its controller characteristics. (c) CSI grid supporting. (d) VSI grid supporting.

- The critical point in IBR controllers is that the controllers usually require a quarter of a power cycle to react to the fault which can be seen in Fig. 9(b) as some sort of disturbance. Therefore, the protective devices should be agile enough to detect the fault in that short period. 


\section{1. Solutions to IBR Protection Issues}

Different methods have been proposed to overcome the protection issues arising from the IBR's where the short-circuit current of the system is quite low. In the next sections, those will be reviewed.

\section{1. 1. Emulation of Synchronous-Generator Fault Response}

One of the methods for enabling protective devices to detect faults is to repeat the synchronous-generator's fault response. The relays largely rely on the high and unbalanced currents generated by synchronous generators for detection of faults [33]. There is a wide body of research working on the development of the negative-sequence current loop to generate currents suitable enough for relays in case of unbalanced faults (e.g., SLG, LL, LLG) as Fig. 12 shows [33] and [34]. Moreover, it should be taken into account that the DC bus usually does not have enough storage capacity for supplying the inverter to make high fault currents.

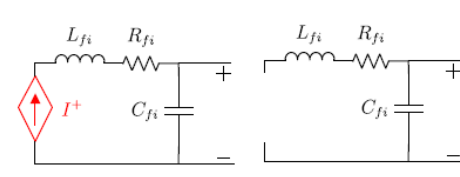

(a)

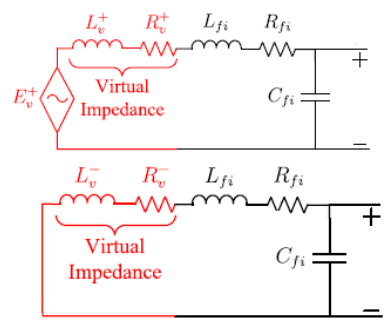

(b)

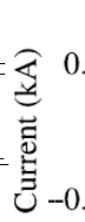

(c)

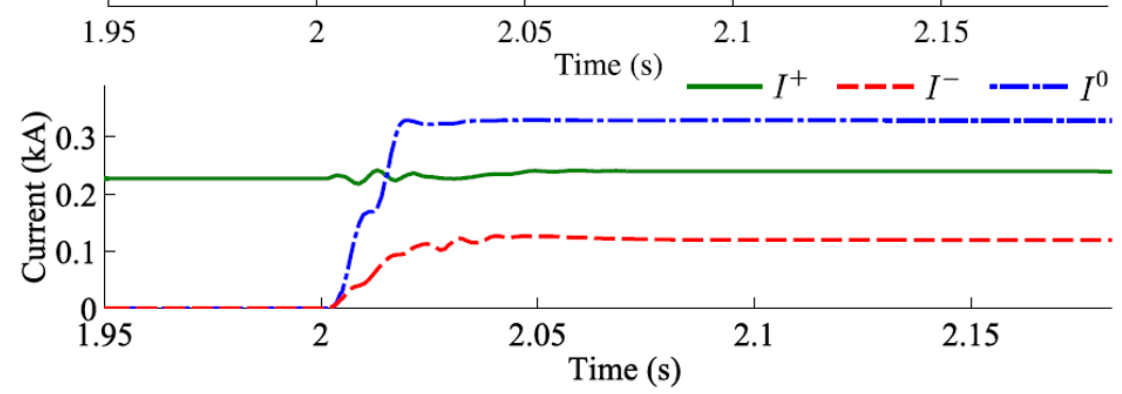

Fig. 12. (a) Conventional positive- and zero-sequence inverter model. (b) Positive- and zerosequence models of the inverters equipped with controllers to mimic generators' fault currents. (c) unbalanced fault response of the inverters with such controllers. This figure is mainly based on [34].

\section{1. 2. Active Protection Methods}

Active protection is defined as injection of sort of waves with a frequency considerably other than the nominal frequency into the grid and identification of faults by means of measuring the parameters of the injected waves [35]. In active protection methods, IBR's are mainly responsible to generate some harmonics. The point is that the intentionally generated harmonics should drastically differ from the ones generated by non-linear loads, saturated transformers, etc. This is critical and extra care should be taken that in the future such harmonic sources will never be added to the grid. There are two ways for harmonic generation as follows:

- Fault-triggered harmonic injection in that IBR's start producing harmonics only after fault occurrence [34], [35], and [36]. The problem with this strategy is that the harmonic generator module should rely on a fault detector as a third party, such as [35] and [36], and correct detection of faults in weak grids with low fault levels is not always possible. In [34], the occurrence of a fault is detected at the location of the IBR when its terminal voltage drops 
below 0.9 p.u. Although [19] necessitates that DER's must keep generating during low voltage situations to meet LVRT requirements, the issue arises from the fact that SLG faults in weak or non-effectively grounded grids do not drop the below range also the voltage drop can be caused by other contingencies such as a cut in generation.

- Continual harmonic injection in which IBR's produce harmonics continuously or repeatedly. This method does not have fault detection problems; however, at the price of reducing power quality and power losses in harmonic generation [28].

\section{Source-Independent Relays}

Considering non-universal fault responses of inverters due to their software-defined and nonstandard structure and control, protective methods independent of the source have been developed. One of the major types of source-independent relays is TW-based relays which are able to detect and locate a wide range of faults in highly complex systems [37] and [38]. When a fault occurs, the fault-induced TW's start moving along TL's as Fig. 13(a) shows. The waves do not depend on the source specifications, but they are dependent on the fault parameters such as fault inception angle, fault impedance, location of the fault, the medium characteristics [39]. Then, TW-based protective devices detect and even locate the fault through the analysis of the wave parameters such as arrival time, peak, polarity, and frequency contents. The key to the efficient function of the TW-based relays is the method used for detection and evaluation of fault-induced waves. Different methods have been used to this end, including sliding-window digital Fourier, Wavelet transformation with different mother wavelets, Hilbert, Short-Time Matrix Pencil Method, and custom-defined methods such as [8]. Korean power transmission network installed several high-frequency measuring devices throughout a part of their system. Having collected their real-time measurements, TW-based relays efficiently detected different faults and the system is working as a prototype for further development [40].
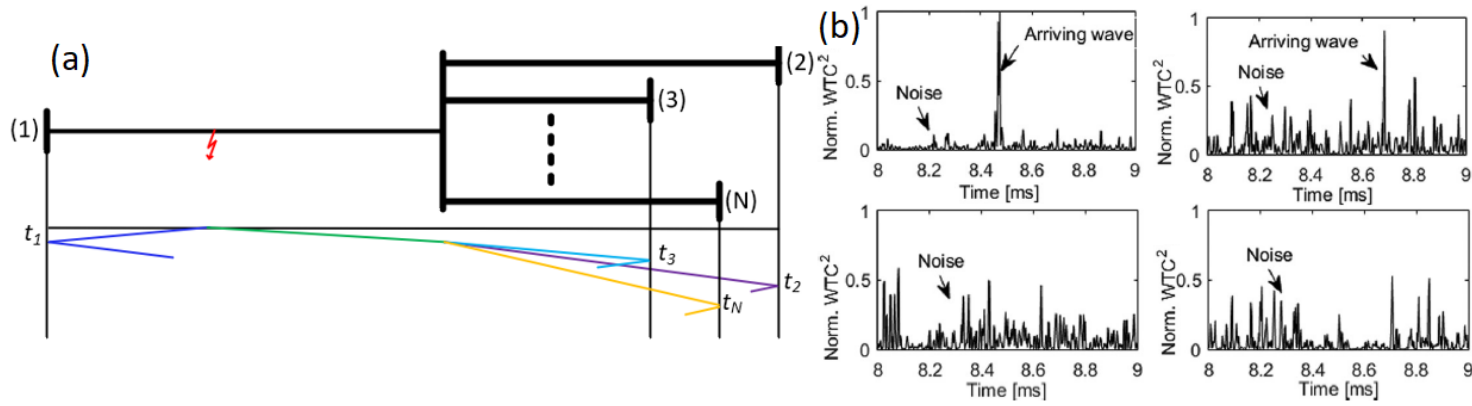

Fig. 13. (s) A typical ladder diagram of TW propagation in an electrical grid. The TW's originate at the fault location and move along the TL's. When they reach discontinuities, they break into parts and each continues traveling. (b) The TW's at the endpoints.

However, TW-based methods are largely prone to measurement noises. If FIA is low, then the TW is likely to vanish in the noises. For example, the two upper sub-figures in Fig. 13(b) show TW's discernible in the noises. however, in the two lower sub-figures, the TW's disappeared in the noises. Also, if there are several discontinuities in the grid, then the wave traveling pattern becomes quite complex which makes the fault detection challenging. One of the practical examples of the TW-based relays is introduced in [41].

\section{Predictive Wide-Area Monitoring, Protection, and Control}


For a profound insight into wide power-outages originating from various unsettling events, it is useful to hypothetically divide power system operation into five situations as depicted in Fig. 14(a) [42].

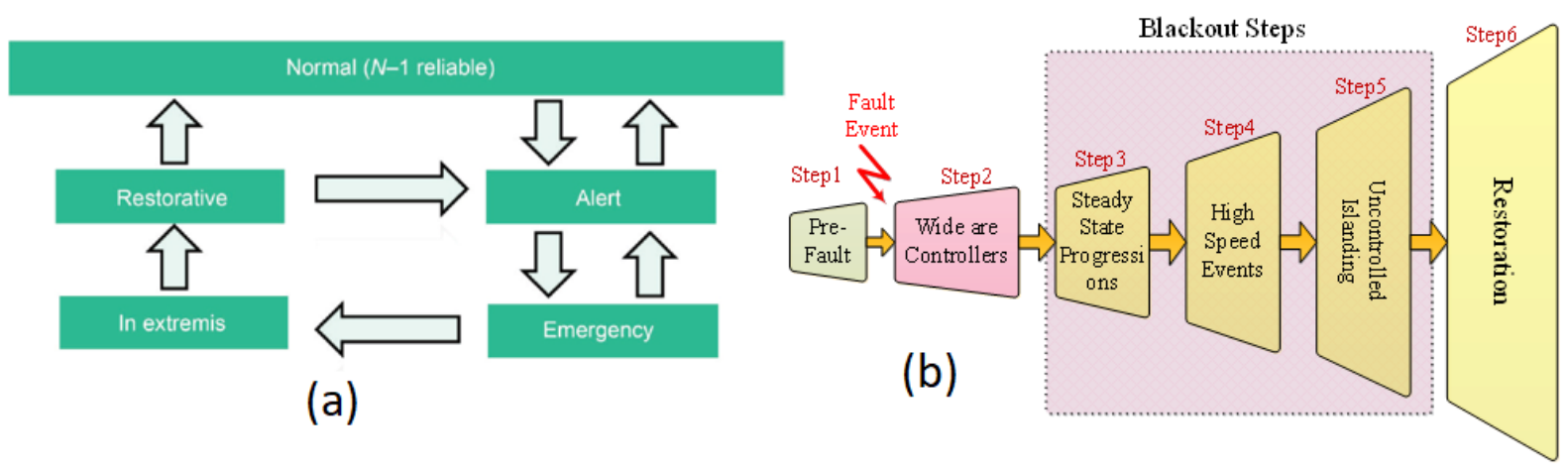

Fig. 14. (a) Operation conditions of power systems [42]. (b) Cascading failures inducing blackouts [43].

\section{1. Cascading Failures in Large Power Systems}

The majority of power outages are resultant of cascading failures initiated by either a fault, line congestions, hardware dysfunction, extreme climate, or wildfires. Fig. 14(b) illustrates the movement of cascading failures. Fig. 15 shows the aggregate substantial power outages from 2011 to 2020 in each continent and also their grounds. It is obvious that severe weather condition is one of the major triggers to the total 250 blackouts.

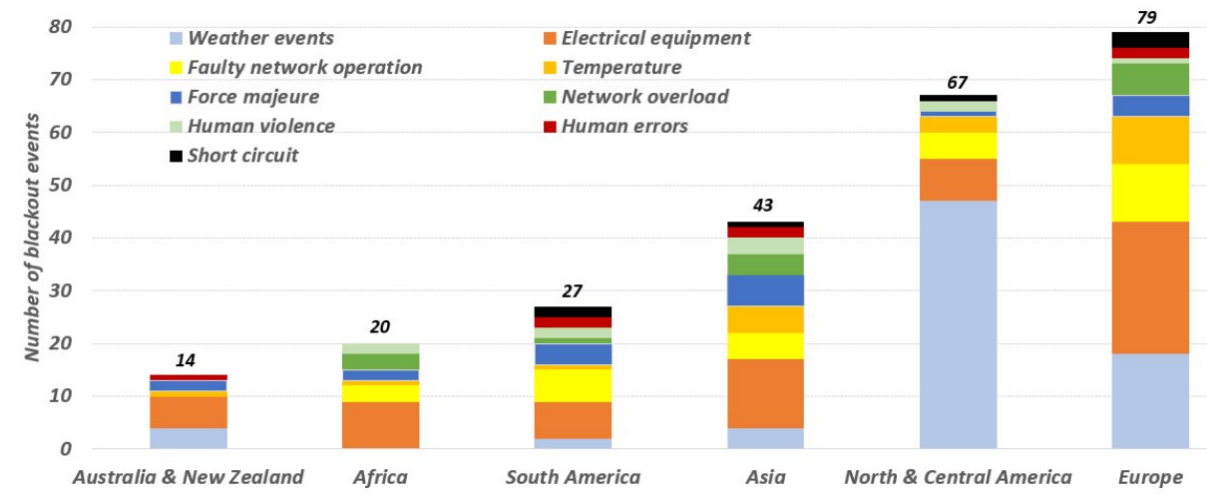

Fig. 15. The number and causes of the blackouts in different continents [43].

\section{2. Estimation Based on Synchronized Measurements}

One of the remedies for reducing the number and intensity of blackouts is the use of PMU's and IED's. However, the power grids are already equipped with SCADA-based measuring devices that does not provide accurate and fast enough data from the purpose of semi-realtime monitoring which is necessary to protection. The basic architecture of protective widearea monitoring is shown in Fig. 16(a). 


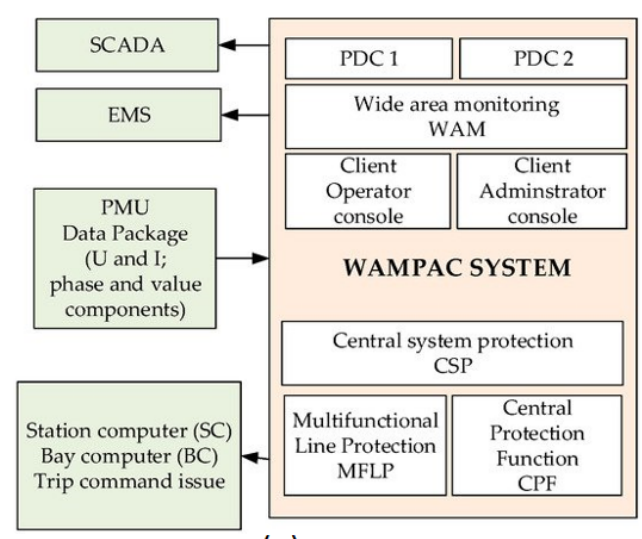

(a)

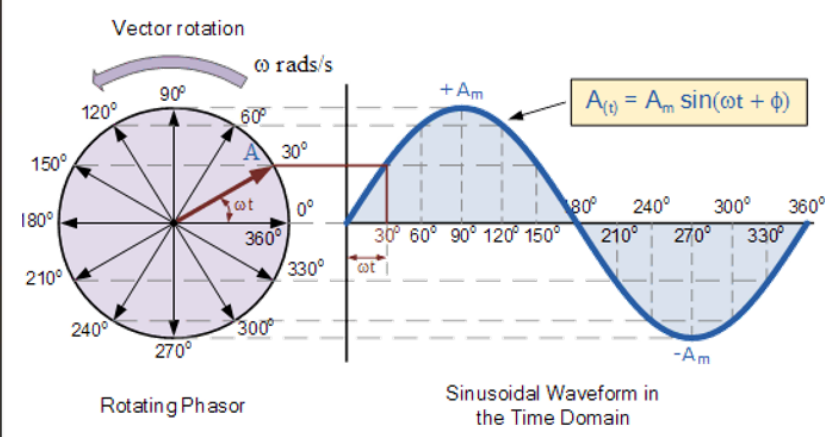

(b)

Fig. 16. (a) The basic structure of the protective wide-area monitoring. (b) Sinusoidal to phasor conversion by PMU's.

With reference to Fig. 16(a), the SMT provides continuous time-stamped estimations. However, the PMU measurements are in the form of phasors which are absolutely different than the data provided by conventional power system metering devices. Figure 16(b) clarifies transformation of a sine wave to a phasor using synchronization technology. The primary idea of PMU's is to measure the voltage and current phasors on distinguishable time arrays, communicate them to a PDC where the data can be evaluated and further processed. The essential functionalities of PMU's are as follows: i) System observing/state estimation. ii) Fault recording.

Although PMU's are beneficial to the system observability, conventional state estimators are not capable of using unprocessed PMU data since there are two major differences between SCADA and PMU measurements. i) The mathematical formulation of conventional state estimators is suitable to SCADA data. ii) The data rate of PMU's is much faster than that of SCADA [44]. Therefore, it is essential to convert PMU data to be compatible with conventional state estimators [45]. The most widely used method for state estimation is WLS which is formulized as,

$$
\min _{\boldsymbol{x}} J(\boldsymbol{x})=[\boldsymbol{z}-\boldsymbol{h}(\boldsymbol{x})]^{T} \boldsymbol{R}^{-1}[\mathbf{z}-\boldsymbol{h}(\boldsymbol{x})]
$$

where $J(\boldsymbol{x})$ is the objective function, $\boldsymbol{R}$ is the measurement-error covariance matrix, $(.)^{T}$ symbolizes matrix transposition. $\boldsymbol{z}$ is the measurement vector. $\boldsymbol{h}(\boldsymbol{x})$ is the system equation, and $\boldsymbol{x}$ is the vector of states. Solving (1) through the Newton-Raphson method results in

$$
\boldsymbol{G}\left(\boldsymbol{x}^{k}\right) \Delta \boldsymbol{x}^{k+1}=\boldsymbol{H}^{T}\left(\boldsymbol{x}^{k}\right) \boldsymbol{R}^{-1}\left[\boldsymbol{z}-\boldsymbol{h}\left(\boldsymbol{x}^{k}\right)\right]
$$

where $\boldsymbol{G}\left(\boldsymbol{x}^{k}\right)=\boldsymbol{H}^{T}\left(\boldsymbol{x}^{k}\right) \boldsymbol{R}^{-1} \boldsymbol{H}\left(\boldsymbol{x}^{k}\right)$ is the gain matrix, $\boldsymbol{H}\left(\boldsymbol{x}^{k}\right)$ is the Jacobian matrix of $\boldsymbol{h}\left(\boldsymbol{x}^{k}\right), \Delta \boldsymbol{x}^{k+1}=\boldsymbol{x}^{k+1}-\boldsymbol{x}^{k}$.

One of the powerful methods to remove the mismatch between the data rates of SCADA and PMU is compressive Sensing that is a way for compression and recovery of a sparse signals only utilizing a small number of linear projections. The sparsity is modeled as, 


$$
x_{j}=z+z_{j}, \quad j \in\{1,2, \ldots, J\}
$$

where $z$ is the common component of compressed signals in that the common component and also the innovation term are both sparse on $\Psi$ which is defined as,

$$
z=\Psi \theta_{z},\left\|\theta_{z}\right\|_{0}=K \text { and } z_{j}=\Psi \theta_{j},\left\|\theta_{j}\right\|_{0}=K_{j}
$$

Then, the vector of sparse coefficients is calculated through

$$
\widehat{\theta}=\arg \min \|\theta\|_{1} \text { s.t. } y=\widehat{\Phi} \widehat{\Psi} \theta
$$

and finally, the signal is recovered by

$$
x=\widehat{\Psi} \theta .
$$

Using compressive sensing the gaps between SCADA and PMU data can be filled by assuming SCADA data as sparsely compressed data [44].

\section{3. Protective Wide-Area Monitoring Structure}

The PWAM framework essentially comprises several layers as shown in Fig. 17. It starts from the sensors connected to the electrical grid that measure electrical parameters, then PMU's using synchronizing signals find the phasor values out of the sensory data and send them to the PDC. The PDC collects a large volume of data and prepares them for recording and visualization as well as other custom-defined applications. The protective algorithms can be implemented as a custom-defined function.

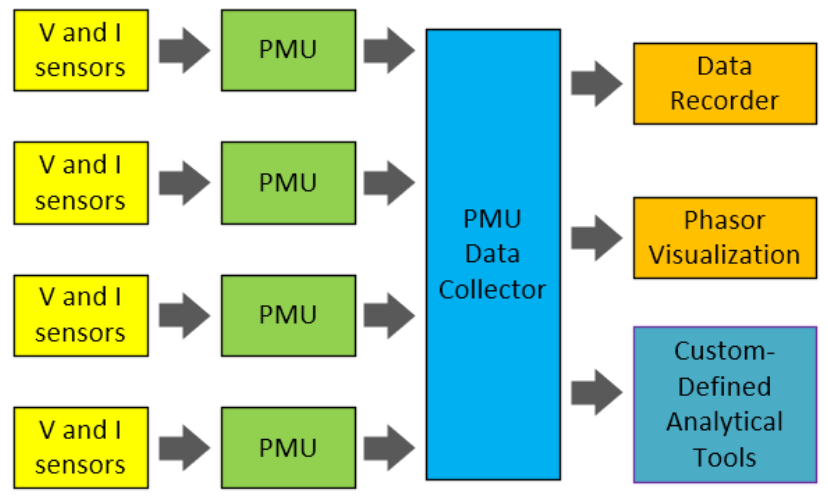

Fig. 17. Different layers for transferring and using PMU data.

However, the protection at this stage has to be backup considering the delays and probable communication failures from the first level to the protection level although the use of PWAM is such accurate and keen that reduces $70 \%$ of significant power outages [46] and 
[47]. There are several studies and real-world PWAM projects as follows: in [48], a multifunctional line protection system is designed using PWAM which is able to prevent false trips due to complicated cases that distance relays falsely trip. Tokyo Electric Power Co. (TEPCO) utilized a wide-area relay technology in light of power angle assessment technique. A major atomic generator was chosen as a locus generator and its momentary power and voltages information were moved to each siphoned stockpiling plant by means of microwave communications. Then, relays used the received and local information to detect oscillations, out of phase, frequency deviations [49].

\section{IoT, Auxiliary Protection and Monitoring Methods}

As smart grid's topology and renewable generations connected to it are both uncertain, a different yet efficient approach is loT which involves the internet for data transmission. The flow of data through the internet keeps relays and monitoring centers aware of the semireal-time changes in the system topology, generation, and demand. However, protection has to be a subordinate auxiliary service of IoT due to loT intermittency and reliability issues [30], [50], and [51].

The ability of machine-to-machine coordination has made loT a matter of greater interest. IoT was first defined in 1999 [52]. As Fig. 18 shows, loT comprises the following portions: i) sensors for collection of data. ii) Identifiers for identification of the data source. iii) Software for analysis of the data. iv) Internet connectivity for communication among all the associated machines.

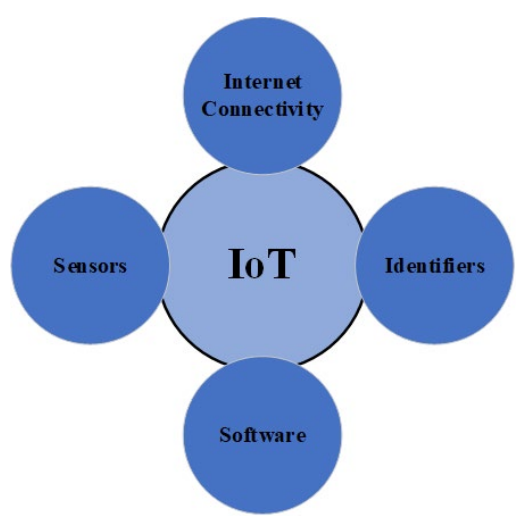

Fig. 18. Components of IoT.

One of the prominent uses of IoT is seen in power systems. The use of IoT in power systems emphasizes i) loT in protection [53]. ii) loT in monitoring [54].

\section{1. IoT in Protection}

IoT-based protection is defined as the protection of equipment and subsystems with the main focus on fault diagnosis and cyber-attacks [55]; however, as the backup protection scheme. The loT-based protection is applicable to situations where the fault is not intense or imminent. For example, In [56], an loT protection scheme is introduced to monitor the distribution transformers' parameters such as temperature, rise or fall of the oil level, vibration, and oil humidity. Upon encountering any abnormality, it alerts the operators, and if no operator is not present onsite, it disconnects the transformers. In [57], another loT-based distribution transformer protection is introduced that monitors overheating, deformation, 
short circuit, and suffocation of windings. The system also stores data and sends alerts to operators upon detecting any abnormality.

\section{Al-based Protection}

The $\mathrm{Al}$ is most popular as it is precise in terms of problem classification and decision making. It optimizes the management strategy as well as involves the process of making an intelligent decision based on its prior training [58]. The Al is defined as the ability of computer systems to solve poorly defined problems using methods inspired by the human brain [59]. Over the years, Al has been implemented in various sectors as well as power systems from the 1990's. Several Al-based monitoring techniques are established and they have proved to be effective [60]. There are several Al methods available, including i) Rule-based systems. ii) Knowledgebased systems. iii) Object-oriented methodologies. iv) Case-based reasoning.

- The rule-based one is defined as a system containing information from human in the form of rules (e.g., If-Then loops). Although it is simple and easily implementable, it is improper in the case of large or scalable systems. Moreover, the lack of flexibility and inability to adapt to changing environments reduces its applications [61].

- The knowledge-based systems are defined as human-centered systems. They attempt to understand and replicate human reactions through the training process. Then, knowledgebased systems use their learning when they encounter new situations. Knowledge-based system applications include after-the-fault analysis and power transmission protection [62].

- The Object-oriented method combines one data object with a specific procedure. Rather than passing data to procedure, the program communicates by sending a message for an object to perform a procedure that is already embedded. It is heavily used in power capacity planning and power system maintenance [63].

- In case-based reasoning, different human experiences are recorded as cases. The system searches the storage with similar problem characteristics and finds the closet fit and applies it to the new ones.

Some of the implemented techniques in this area are: Artificial Neural network (ANN) [64] and [65], Support Vector Machine (SVM) [66], Genetic Algorithm (GA) [7], Fuzzy Logic [67], and Matching Approach [68]. Each one of them has a different algorithm to monitor and protect the power grids.

\section{1. Relays based on ANN}

ANN is one of the most prominent intelligent techniques used for power system monitoring and protection purposes. ANN shows a number of such qualities as mapping capacities, adaption of the internal failure, speculation, fast data preparation [69]. ANN is essentially based on pattern recognition and training. The output decision is determined by comparison with the previous results during training procedure [70].

\section{- Transformer Protection with ANN}

In [71], the author has applied the finite impulse response ANN (FIRANN) where it is used in a differential relay for protection of three-phase power transformers. Two different FIRANN were applied where one was involved in determining the existence of the fault and the other one indicates whether the fault is inside the transformer. In [72], the authors have used ANN for detection of magnetization level in transformer cores. As the magnetic core saturation is 
directly related to the current harmonics, the method detects saturation through analysis of the current harmonics. In [73], an ANN-based algorithm is developed that determines the transformer health investigating dissolved gases in the oil (e.g., Hydrogen $\left(\mathrm{H}_{2}\right)$, Methane $\left(\mathrm{CH}_{4}\right)$, Ethene $\left(\mathrm{C}_{2} \mathrm{H}_{6}\right)$, Carbon Monoxide $\left.(\mathrm{CO})\right)$ which are created from stresses on transformers such as internal sparking and overheating. In [74], an ANN-based differential protection is designed that is able to distinguish different events such as inrush currents, sympathetic inrush, and overexcitation.

\section{- Generator Protection with ANN}

In [75], the authors have proposed an ANN-based detection and classification of winding faults in windmill generators. The authors have concluded that ANN-based algorithm provides higher accuracy at a small computation cost. In [76], an ANN-based method for detecting loss of excitation (LOE) in synchronous generators is proposed. The ability of generator protection in differentiating LOE and stable power swing is essential for enhancing the traditional LOE protection. The results clearly demonstrate that the ANN-based method has a promising performance compared to conventional generator protection relays.

\section{- Transmission Line Protection with ANN}

Another prominent application of ANN is the protection of TL's. In [71], an ANN-based method for the protection of TL's is developed. As power systems are integrated and complex, the ANN is trained with 100,000 patterns. Therefore, for more complex systems, training the ANN algorithm can be quite time-consuming if it is even technically possible. In [77], the researchers have established an ANN-based system with 99.91\% fault classification accuracy. Although the established system provides greater success in fault classification, it lacks the capability of fault location in the system. In [78], the authors have presented a novel filter premised on ANN for fault detection, classification, and location. The results show that the accuracy is almost $96 \%$. Another point of strength of ANN-based systems is its fast response time. In [79], the authors have proposed an ANN-based ultrafast fault detection system that has satisfactory classification accuracy with one-eighth of a cycle of post-event data. In [80], the authors have established an ANN-based protection system for STATCOM compensated TL's where the detection, classification, and location of the fault is done in a quarter cycle ( $4 \mathrm{~ms}$ in case of $60 \mathrm{~Hz}$ system) which is suitable for IBR-based systems.

\section{- Detection of High Impedance Faults with ANN}

Another application of ANN is to detect high impedance faults (HIF's) in distribution systems with IBR's [81]. This is due to the fact that HIF's are difficult to be monitored using traditional digital relaying as their current is too low to detect and in some cases, the fault current is only available during a short time duration. In [81], the input data are local current and voltage. The features of HIF's then will be detected by the proposed method and it not only finds an HIF fault, but it also finds the location of the HIF in IBR-based grids.

\section{- ANN for Cyber Security}

Another aspect of ANN is its application in the cyber-security of power systems. As modern power systems involve an abundant number of cyber resources, it is evident that cyberattacks may be planned to cripple down the system most treacherously by 'data spoofing' (i.e., gaining control of the system in disguise of trusted people). For cyber-attack detection, 
an ANN-based algorithm is proposed in that the algorithm shows more flexibility in detection of attacks when the system does not work pursuing prior assumptions [82]. In [83], the author had compared the state-of-the-art techniques and inferred that through ANN, cyberattacks can be prevented in cyber-physical systems such as smart-grid. Moreover, along with the data spoofing, false data injection is also seen as a major threat in cyber protection which ANN is able to detect them. The authors of [84] proposed an ANN-based algorithm that detects $92-99.5 \%$ of false injected data, and consequently, the protection system has a minimum number of false alarms. The ANN-based algorithm demonstrates stronger robustness than Multiple Nonlinear Regression (MNR) for the wind power forecasting against the false data injection attacks [85]. Another application of ANN is to detect the reason for a reported event in the system whether it has a real source such as faults or it is initiated only based on communications failure or data-attacks. This is critical especially when the event has a short duration and long-window filters and detectors are not able to detect that or wrongly classify that as a noise [86] and [87].

\section{Disadvantages of ANN}

Although ANN involves a vast area of power system application, it brings up some points of concern such as the need for a large training set, the issue of obtaining a stable solution as well as the danger of over-fitting [58]. Therefore, other Al algorithms have been established such as Support Vector Machine (SVM), and Fuzzy logic. The application of them in power system protection will be described in the next parts.

\section{2. Relays based on Support Vector Machine}

The disadvantages of ANN created serious concerns on power system protection and monitoring. Another approach is Support Vector Machine. Similar to the ANN, SVM also has been applied to different protection purposes. For those purposes, SVM-based techniques have played a key role and established themselves promising in power system protection. In SVM, a generalized model is created for a certain purpose via analysis of a certain data set. Then, parts of the data set are divided by planes defined as Hyperplanes. Additional planes are created as the margins for the prime hyperplane. The marginal planes are established with respect to the nearest data or dataset available in the plane. These data or datasets are known as support vectors. By this, a generalized model is founded. Then SVM classifies new data to be in which one of the datasets [88]. SVM mainly has wide applications in classification and event detection.

\section{- SVM for Transformer Protection}

Similar to ANN-based systems, SVM-based techniques are also applied to transformer protection. In [89], an SVM-based fault classification is proposed for transformers. It is capable of classifying in-zone and out-of-the-zone faults more reliably compared to ANNbased algorithms. In [90], an SVM-based protection technique is proposed. It monitors magnetization hysteresis loop by voltage-differential current (V-DCurr) curves. It pinpoints faults by detection of changes in the hysteresis loop trajectory. The algorithm achieves a success rate greater than $98 \%$. In [91], SVM is exploited to discriminate if the differential current $(\Delta I)$ is caused by CT saturation or internal faults.

\section{- Generator Protection using SVM}


The SVM-based techniques are also employed for generator protection. In [92], the authors have proposed SVM-based techniques for identification of generator loss-of-excitation (LOE). In this technique, the SVM-based method is able to identify the LOE condition moderately fast before the power-flow direction changes. In [93], the LOE detection is advanced to a degree that the relay using SVM-based logic is able to differentiate total and partial LOE in synchronous generators. In [94], an SVM-based fault detection and classification technique is proposed that detects small spikes in the stator winding of synchronous generators, while the conventional generator relays are unable to find.

\section{- Transmission Line Protection with SVM}

Protection of TL's is also an important task for the SVM-based techniques. In [95], the authors used SVM for fault location, and their comparative study finds that SVM-based techniques are superior to ANN-based ones in this regard. In [96], the researchers have established an SVM-based protection algorithm for a multi-terminal high-voltage direct current (MT-HVDC) system. This protection algorithm has been able to identify, classify, and locate the fault within $0.15 \mathrm{~ms}$, ensuring speedy DC grid protection. In [97], the authors proposed an effective method for fault location in TL's that uses the fundamental components of voltages and currents of the faulty phases for fault detection and location. In [98], the researchers have used the radial basis function (RBF) neural network and SVM to identify the fault. This method utilizes three-phase voltage measurements, but it does not require current measurements. The authors of [99] used SVM as an intelligent tool to discriminate between different zonal faults in TL's in that apparent impedance values are collected from distance relay under different fault conditions. Then, after SVM gets trained, SVM is able to identify different faults along the TL. In [100], SVM is employed for fault classification in a series compensated TL with a fixed capacitor which is placed at the center of the line. The method is able to successfully detect and locate the faults even during line energization.

\section{- SVM for Cyber Security}

SVM-based methods are also beneficial to power system cyber-security. In the 21st century, the reliability of the power systems largely depends on cyber protection. In [101], the authors have proposed an SVM-based malicious data detection and classification method. The results proves that the method is successfully able to classify intrusion data. Thus, cyber-security of power grids can be improved using SVM. In [102], the authors have proposed a cyber intrusion protection system in that SVM is used for detecting suspicious behaviors of smart meters. In [103], SVM is utilized for dynamic security assessment of grids in which the changes of phase angles throughout the system are monitored and suspicious deviations are detected.

\section{- Disadvantages of SVM}

Although SVM demonstrated a great rate of success in event classification, there are some specific drawbacks in the application of SVM. For example, there are concerns about SVM real-time function since it is computationally expensive and needs large volumes of reliable memory in industrial and noisy environments. In addition, the training process is slower compared to ANN [104].

\section{3. Fuzzy Logic}


Fuzzy logic is an approach to evaluating the degree of situation/incident/problem, converse to the Boolean logic which defines the case as a whole true/false. For example, a fault in a TL can be defined for computers by ' 0 ' as 'no fault' and ' 1 ' as 'fault'. But in fuzzy logic, the fault might be a range within ' 0 ' to ' 1 ' by defining ' 0.2 ' as a mild fault, '0.4' general fault, '0.6' strong fault, '0.9' as an extreme fault. By this, a new algorithm can be set to train the situation for a qualitative assessment of power system apparatus. Fuzzy logic can be used similar to ANN and SVM. However, it is capable of protecting power systems based on the severity of the fault. For example, an SLG fault in a non-grounded system sensitive to power disconnection can be postponed until a proper time, but an LL fault should be addressed almost without any delay. In [105], a fuzzy-logic algorithm is introduced for recognizing inrush currents in transformers. A fuzzy-logic-based method for turn-to-turn faults is devised in [106]. In [106], a novel method is proposed based on fuzzy logic for synchronous generator protection in which the fuzzy logic-based method is designed for fault identification and detection with high sensitivity. But, the high sensitivity is not going to reduce the selectivity of the system in case of minor faults. In [107], a fuzzy logic-based fault detection algorithm is developed for series compensated TL's. The algorithm was extensively tested with a wide range of operating conditions. The results demonstrate its effectiveness and robustness against various FIA's, load angles, and source impedance. In [108], faults in double line TLS are successfully detected and located with the use of fuzzy logic. The results show strong evidence that the system is fast and reliable in detection of faults at different locations along the TL. Regardless of fuzzy logic advantages, it has the major problem of determining global extremums.

\section{References}

[1] A. Mahmood, N. Javaid, and S. Razzaq, "A review of wireless communications for smart grid," Renewable and Sustainable Energy Reviews, vol. 41, pp. 248-260, Jan. 2015, doi: https://doi.org/10.1016/j.rser.2014.08.036.

[2] J. Gao et al., "Grid Monitoring: Secured Sovereign Blockchain Based Monitoring on Smart Grid," IEEE Access, vol. 6, pp. 9917-9925, 2018, doi: 10.1109/ACCESS.2018.2806303.

[3] B. B. Alagoz, A. Kaygusuz, and A. Karabiber, "A user-mode distributed energy management architecture for smart grid applications," Energy, vol. 44, no. 1, pp. 167-177, Aug. 2012, doi: https://doi.org/10.1016/i.energy.2012.06.051.

[4] S. Ci, N. Lin, Y. Zhou, H. Li, and Y. Yang, "A New Digital Power Supply System for Fog and Edge Computing," in 2018 14th International Wireless Communications \& Mobile Computing Conference (IWCMC), 25-29 Jun. 2018, pp. 1513-1517, doi: 10.1109/IWCMC.2018.8450497.

[5] M. Manohar, E. Koley, and S. Ghosh, "Microgrid protection under wind speed intermittency using extreme learning machine," Computers \& Electrical Engineering, vol. 72, pp. 369-382, Nov. 2018, doi: https://doi.org/10.1016/j.compeleceng.2018.10.005.

[6] M. H. Rehmani, M. Reisslein, A. Rachedi, M. Erol-Kantarci, and M. Radenkovic, "Integrating Renewable Energy Resources Into the Smart Grid: Recent Developments in Information and Communication Technologies," IEEE Transactions on Industrial Informatics, vol. 14, no. 7, pp. 2814-2825, 2018, doi: 10.1109/TII.2018.2819169.

[7] R. Jalilzadeh Hamidi, A. Ahmadian, R. Patil, and A. Asadinejad, "Optimal time-current graded coordination of multistage inverse-time overcurrent relays in distribution networks," International Transactions on Electrical Energy Systems, vol. 29, no. 5, p. e2841, 2019, doi: https://doi.org/10.1002/2050-7038.2841.

[8] R. J. Hamidi and H. Livani, "A Recursive Method for Traveling-Wave Arrival-Time Detection in Power Systems," IEEE Transactions on Power Delivery, vol. 34, no. 2, pp. 710-719, 2019, doi: 10.1109/TPWRD.2018.2877705. 
[9] Department of Energy's Advanced Grid Research and Development. https://www.smartgrid.gov/adms research and development (accessed.

[10] C. Li, P. Rakhra, P. Norman, P. Niewczas, G. Burt, and P. Clarkson, "Modulated Low FaultEnergy Protection Scheme for DC Smart Grids," IEEE Transactions on Smart Grid, vol. 11, no. 1, pp. 84-94, 2020, doi: 10.1109/TSG.2019.2917540.

[11] S. Rahman Fahim, S. K. Sarker, S. M. Muyeen, M. R. I. Sheikh, and S. K. Das, "Microgrid Fault Detection and Classification: Machine Learning Based Approach, Comparison, and Reviews," Energies, vol. 13, no. 13, p. 3460, 2020. [Online]. Available: https://www.mdpi.com/1996$1073 / 13 / 13 / 3460$.

[12] S. Lotfifard, J. Faiz, and M. Kezunovic, "Over-current relay implementation assuring fast and secure operation in transient conditions," Electric Power Systems Research, vol. 91, pp. 1-8, 2012/10/01/ 2012, doi: https://doi.org/10.1016/i.epsr.2012.02.001.

[13] M. Yousaf, K. M. Muttaqi, and D. Sutanto, "A Control Strategy to Mitigate the Sensitivity Deterioration of Overcurrent Protection in Distribution Networks With the Higher Concentration of the Synchronous and Inverter-Based DG Units," IEEE Transactions on Industry Applications, vol. 57, no. 3, pp. 2298-2306, 2021, doi: 10.1109/TIA.2021.3057304.

[14] H. S. Pandya, D. M. Pandeji, R. K. Iyer, and P. M. Purohit, "Digital protection strategy of microgrid with relay time grading using particle swarm optimization," in 2015 5th Nirma University International Conference on Engineering (NUiCONE), 26-28 Nov. 2015, pp. 1-6, doi: 10.1109/NUICONE.2015.7449612.

[15] L. Guo, C. Ye, Y. Ding, and P. Wang, "Allocation of Centrally Switched Fault Current Limiters Enabled by 5 G in Transmission System," IEEE Transactions on Power Delivery, vol. 36, no. 5, pp. 3231-3241, 2021, doi: 10.1109/TPWRD.2020.3037193.

[16] V. C. Nikolaidis, A. M. Tsimtsios, and A. S. Safigianni, "Investigating Particularities of Infeed and Fault Resistance Effect on Distance Relays Protecting Radial Distribution Feeders With DG," IEEE Access, vol. 6, pp. 11301-11312, 2018, doi: 10.1109/ACCESS.2018.2804046.

[17] S. Biswas and V. Centeno, "A communication based infeed correction method for distance protection in distribution systems," in 2017 North American Power Symposium (NAPS), 17-19 Sep. 2017, pp. 1-5, doi: 10.1109/NAPS.2017.8107226.

[18] M. Usama et al., "A Comprehensive Review on Protection Strategies to Mitigate the Impact of Renewable Energy Sources on Interconnected Distribution Networks," IEEE Access, vol. 9, pp. 35740-35765, 2021, doi: 10.1109/ACCESS.2021.3061919.

[19] "IEEE Standard for Interconnection and Interoperability of Distributed Energy Resources with Associated Electric Power Systems Interfaces - Redline," IEEE Std 1547-2018 (Revision of IEEE Std 1547-2003) - Redline, pp. 1-227, 2018.

[20] "IEEE Application Guide for IEEE Std 1547(TM), IEEE Standard for Interconnecting Distributed Resources with Electric Power Systems," IEEE Std 1547.2-2008, pp. 1-217, 2009, doi: 10.1109/IEEESTD.2008.4816078.

[21] Y. M. Makwana and B. R. Bhalja, "Experimental Performance of an Islanding Detection Scheme Based on Modal Components," IEEE Transactions on Smart Grid, vol. 10, no. 1, pp. 1025-1035, 2019, doi: 10.1109/TSG.2017.2757599.

[22] C. R. Reddy, B. S. Goud, B. N. Reddy, M. Pratyusha, C. V. V. Kumar, and R. Rekha, "Review of Islanding Detection Parameters in Smart Grids," in 2020 8th International Conference on Smart Grid (icSmartGrid), 17-19 Jun. 2020, pp. 78-89, doi: 10.1109/icSmartGrid49881.2020.9144923.

[23] N. Fischer. "Protection of Inverter-Based Resources." Energy Systems Integration Group. https://www.esig.energy/protection-of-inverter-based-resources/ (accessed 31/12/2021.

[24] M. Nagpal, M. Jensen, and Michael Higginson, "Protection Challenges and Practices for Interconnecting Inverter Based Resources to Utility Transmission Systems," in "Impact of Inverter Based Resources on Utility Transmission System Protection," IEEE Power \& Energy Society, USA, Jul. 2020. 
[25] G. Kobet and P. Pourbeik, "Impact of Inverter Based Generation on Bulk Power System Dynamics and Short-Circuit Performance," IEEE PES Resource Center, Apr. 2019.

[26] J. Keller and B. Kroposki, "Understanding Fault Characteristics of Inverter-Based Distributed Energy Resources," National Renewable Energy Labratory, USA, Jan. 2010.

[27] M. A. U. Khan, Q. Hong, A. Dyśko, C. Booth, B. Wang, and X. Dong, "Evaluation of Fault Characteristic in Microgrids Dominated by Inverter-Based Distributed Generators with Different Control Strategies," in 2019 IEEE 8th International Conference on Advanced Power System Automation and Protection (APAP), 21-24 Oct. 2019, pp. 846-849, doi: 10.1109/APAP47170.2019.9224706.

[28] S. Ravyts, G. V. d. Broeck, L. Hallemans, M. D. Vecchia, and J. Driesen, "Fuse-Based ShortCircuit Protection of Converter Controlled Low-Voltage DC Grids," IEEE Transactions on Power Electronics, vol. 35, no. 11, pp. 11694-11706, 2020, doi: 10.1109/TPEL.2020.2988087.

[29] Z. Shuai, C. Shen, X. Yin, X. Liu, and Z. J. Shen, "Fault Analysis of Inverter-Interfaced Distributed Generators With Different Control Schemes," IEEE Transactions on Power Delivery, vol. 33, no. 3, pp. 1223-1235, 2018, doi: 10.1109/TPWRD.2017.2717388.

[30] "IEEE Standard Conformance Test Procedures for Equipment Interconnecting Distributed Energy Resources with Electric Power Systems and Associated Interfaces," IEEE Std 1547.12020, pp. 1-282, 2020, doi: 10.1109/IEEESTD.2020.9097534.

[31] M. Castilla, J. Miret, A. Camacho, J. Matas, and L. G. d. Vicuna, "Reduction of Current Harmonic Distortion in Three-Phase Grid-Connected Photovoltaic Inverters via Resonant Current Control," IEEE Transactions on Industrial Electronics, vol. 60, no. 4, pp. 1464-1472, 2013, doi: 10.1109/TIE.2011.2167734.

[32] H. Han, X. Hou, J. Yang, J. Wu, M. Su, and J. M. Guerrero, "Review of Power Sharing Control Strategies for Islanding Operation of AC Microgrids," IEEE Transactions on Smart Grid, vol. 7, no. 1, pp. 200-215, 2016, doi: 10.1109/TSG.2015.2434849.

[33] D. Kelly, P. Mysore, and N. Mohan, "A Novel Control Scheme for Utility-Scale Inverter-Based Resources to Emulate Synchronous Generator Fault Response and Retain Existing Protection Infrastructure," in 2021 74th Conference for Protective Relay Engineers (CPRE), 22-25 Mar. 2021, pp. 1-7, doi: 10.1109/CPRE48231.2021.9429836.

[34] A. Banaiemoqadam, A. Hooshyar, and M. A. Azzouz, "A Comprehensive Dual Current Control Scheme for Inverter-Based Resources to Enable Correct Operation of Protective Relays," IEEE Transactions on Power Delivery, vol. 36, no. 5, pp. 2715-2729, 2021, doi: 10.1109/TPWRD.2020.3025878.

[35] A. Soleimanisardoo, H. K. Karegar, and H. H. Zeineldin, "Differential Frequency Protection Scheme Based on Off-Nominal Frequency Injections for Inverter-Based Islanded Microgrids," IEEE Transactions on Smart Grid, vol. 10, no. 2, pp. 2107-2114, 2019, doi: 10.1109/TSG.2017.2788851.

[36] M. A. U. Khan, Q. Hong, A. Dyśko, and C. Booth, "An active protection scheme For islanded microgrids," in 15th International Conference on Developments in Power System Protection (DPSP 2020), 9-12 Mar. 2020, pp. 1-6, doi: 10.1049/cp.2020.0020.

[37] R. J. Hamidi, H. Livani, and R. Rezaiesarlak, "Traveling-Wave Detection Technique Using Short-Time Matrix Pencil Method," IEEE Transactions on Power Delivery, vol. 32, no. 6, pp. 2565-2574, 2017, doi: 10.1109/TPWRD.2017.2685360.

[38] S. Wei, G. Yanfeng, and L. Yan, "Traveling-wave-based fault location algorithm for starconnected hybrid multi-terminal HVDC system," in 2017 IEEE Conference on Energy Internet and Energy System Integration (EI2), 26-28 Nov. 2017, pp. 1-5, doi: 10.1109/EI2.2017.8245645.

[39] R. J. Hamidi and H. Livani, "A travelling wave-based fault location method for hybrid threeterminal circuits," in 2015 IEEE Power \& Energy Society General Meeting, 26-30 Jul. 2015, pp. 1-5, doi: 10.1109/PESGM.2015.7286247. 
[40] J. W. Lee, W. K. Kim, J. Han, W. H. Jang, and C. H. Kim, "Fault area estimation using traveling wave for wide area protection," Journal of Modern Power Systems and Clean Energy, vol. 4, no. 3, pp. 478-486, 2016, doi: 10.1007/s40565-016-0222-7.

[41] Selinc. "SEL-T400L." https://selinc.com/products/T400L/ (accessed.

[42] J. He, L. Liu, W. Li, and M. Zhang, "Development and research on integrated protection system based on redundant information analysis," Protection and Control of Modern Power Systems, vol. 1, no. 1, p. 13, Oct. 2016, doi: 10.1186/s41601-016-0024-y.

[43] G. Jurišić, J. Havelka, T. Capuder, and S. Sučić, "Laboratory Test Bed for Analyzing FaultDetection Reaction Times of Protection Relays in Different Substation Topologies," Energies, vol. 11, no. 9, p. 2482, 2018. [Online]. Available: https://www.mdpi.com/1996$1073 / 11 / 9 / 2482$.

[44] R. J. Hamidi, H. Khodabandehlou, H. Livani, and M. S. Fadali, "Application of distributed Compressive Sensing to Power System State Estimation," in 2015 North American Power Symposium (NAPS), 4-6 Oct. 2015, pp. 1-6, doi: 10.1109/NAPS.2015.7335114.

[45] R. J. Hamidi, H. Khodabandelou, H. Livani, and M. Sami-Fadali, "Hybrid state estimation using distributed Compressive Sensing," in 2016 IEEE Power and Energy Society General Meeting (PESGM), 17-21 Jul. 2016, pp. 1-5, doi: 10.1109/PESGM.2016.7742038.

[46] J. Wen, W. H. E. Liu, P. L. Arons, and S. K. Pandey, "Evolution Pathway Towards Wide Area Monitoring and Protection-A Real-World Implementation of Centralized RAS System," IEEE Transactions on Smart Grid, vol. 5, no. 3, pp. 1506-1513, 2014, doi: 10.1109/TSG.2013.2278660.

[47] M. M. Eissa, "A Novel Centralized Wide Area Protection "CWAP" in Phase Portrait Based on Pilot Wire Including Phase Comparison," IEEE Transactions on Smart Grid, vol. 10, no. 3, pp. 2671-2682, 2019, doi: 10.1109/TSG.2018.2808207.

[48] I. Ivanković, I. Kuzle, and N. Holjevac, "Wide Area Information-Based Transmission System Centralized Out-of-Step Protection Scheme," Energies, vol. 10, no. 5, p. 633, 2017. [Online]. Available: https://www.mdpi.com/1996-1073/10/5/633.

[49] W. G. C-6, "Wide Area Protection and Emergency Control," IEEE Power Engineering Society, USA.

[50] J. M. Carrasco et al., "Power-Electronic Systems for the Grid Integration of Renewable Energy Sources: A Survey," IEEE Transactions on Industrial Electronics, vol. 53, no. 4, pp. 1002-1016, 2006, doi: 10.1109/TIE.2006.878356.

[51] F. Blaabjerg, R. Teodorescu, M. Liserre, and A. V. Timbus, "Overview of Control and Grid Synchronization for Distributed Power Generation Systems," IEEE Transactions on Industrial Electronics, vol. 53, no. 5, pp. 1398-1409, 2006, doi: 10.1109/TIE.2006.881997.

[52] L. Atzori, A. lera, and G. Morabito, "The Internet of Things: A survey," Computer Networks, vol. 54, no. 15, pp. 2787-2805, Oct. 2010, doi: https://doi.org/10.1016/i.comnet.2010.05.010.

[53] W. Liao, S. Salinas, M. Li, P. Li, and K. A. Loparo, "Cascading Failure Attacks in the Power System: A Stochastic Game Perspective," IEEE Internet of Things Journal, vol. 4, no. 6, pp. 2247-2259, 2017, doi: 10.1109/JIOT.2017.2761353.

[54] D. Santos and J. C. Ferreira, "IoT Power Monitoring System for Smart Environments," Sustainability, vol. 11, no. 19, p. 5355, 2019. [Online]. Available: https://www.mdpi.com/2071-1050/11/19/5355.

[55] I. Lee and K. Lee, "The Internet of Things (IOT): Applications, investments, and challenges for enterprises," Business Horizons, vol. 58, no. 4, pp. 431-440, Jul. 2015, doi: https://doi.org/10.1016/j.bushor.2015.03.008.

[56] D. Srivastava and M. M. Tripathi, "Transformer Health Monitoring System Using Internet of Things," in 2018 2nd IEEE International Conference on Power Electronics, Intelligent Control and Energy Systems (ICPEICES), 22-24 Oct. 2018, pp. 903-908, doi: 10.1109/ICPEICES.2018.8897325. 
[57] H. Jamal, M. F. N. Khan, A. Anjum, and M. K. Janjua, "Thermal Monitoring and Protection for Distribution Transformer Under Residential Loading Using Internet of Things," in 2018 IEEE Global Conference on Internet of Things (GCloT), 5-7 Dec. 2018, pp. 1-6, doi: 10.1109/GCloT.2018.8620135.

[58] B. P. Bhattarai et al., "Big data analytics in smart grids: state-of-the-art, challenges, opportunities, and future directions," IET Smart Grid, vol. 2, no. 2, pp. 141-154, 2019, doi: https://doi.org/10.1049/iet-stg.2018.0261.

[59] S. Koranne, "Artificial Intelligence and Optimization," in Handbook of Open Source Tools: Springer, 2011, ch. 18, pp. 391-392.

[60] S. S. Gururajapathy, H. Mokhlis, and H. A. Illias, "Fault location and detection techniques in power distribution systems with distributed generation: A review," Renewable and Sustainable Energy Reviews, vol. 74, pp. 949-958, Jul. 2017, doi: https://doi.org/10.1016/i.rser.2017.03.021.

[61] C. Grosan and A. Abraham, Rule-Based Expert Systems. Berlin, Germany: Springer, 2011.

[62] E. Orduna, F. Garces, and E. Handschin, "Algorithmic-knowledge-based adaptive coordination in transmission protection," IEEE Transactions on Power Delivery, vol. 18, no. 1, pp. 61-65, 2003, doi: 10.1109/TPWRD.2002.806683.

[63] K. Kawahara, H. Sasaki, J. Kubokawa, H. Asahara, and K. Sugiyama, "A proposal of a supporting expert system for outage planning of electric power facilities retaining high power supply reliability," IEEE Transactions on Power Systems, vol. 13, no. 4, pp. 1453-1458, 1998, doi: 10.1109/59.736289.

[64] A. R. Bahmanyar and A. Karami, "Power system voltage stability monitoring using artificial neural networks with a reduced set of inputs," International Journal of Electrical Power \& Energy Systems, vol. 58, pp. 246-256, Jun. 2014, doi: https://doi.org/10.1016/j.ijepes.2014.01.019.

[65] S. A. Siddiqui, K. Verma, K. R. Niazi, and M. Fozdar, "Real-Time Monitoring of Post-Fault Scenario for Determining Generator Coherency and Transient Stability Through ANN," IEEE Transactions on Industry Applications, vol. 54, no. 1, pp. 685-692, 2018, doi: 10.1109/TIA.2017.2753176.

[66] Z. Yang, Q. Zhou, X. Wu, and Z. Zhao, "A Novel Measuring Method of Interfacial Tension of Transformer Oil Combined PSO Optimized SVM and Multi Frequency Ultrasonic Technology," IEEE Access, vol. 7, pp. 182624-182631, 2019, doi: 10.1109/ACCESS.2019.2954899.

[67] S. Zhang, Y. Mishra, and M. Shahidehpour, "Fuzzy-Logic Based Frequency Controller for Wind Farms Augmented With Energy Storage Systems," IEEE Transactions on Power Systems, vol. 31, no. 2, pp. 1595-1603, 2016, doi: 10.1109/TPWRS.2015.2432113.

[68] H. Mokhlis and H. Li, "Non-linear representation of voltage sag profiles for fault location in distribution networks," International Journal of Electrical Power \& Energy Systems, vol. 33, no. 1, pp. 124-130, Jan. 2011, doi: https://doi.org/10.1016/i.ijepes.2010.06.020.

[69] A. Prasad, J. Belwin Edward, and K. Ravi, "A review on fault classification methodologies in power transmission systems: Part-l," Journal of Electrical Systems and Information Technology, vol. 5, no. 1, pp. 48-60, May 2018, doi: https://doi.org/10.1016/i.jesit.2017.01.004.

[70] I. N. d. Silva, D. H. Spatti, R. A. Flauzino, L. H. B. Liboni, and S. F. d. R. Alves, "Artificial Neural Network Architectures and Training Processes," in Artificial Neural Networks: Springer, 2017, ch. 2, pp. 25-27.

[71] A. L. Orille-Fernandez, N. K. I. Ghonaim, and J. A. Valencia, "A FIRANN as a differential relay for three phase power transformer protection," IEEE Transactions on Power Delivery, vol. 16, no. 2, pp. 215-218, 2001, doi: 10.1109/61.915485.

[72] K. Dezelak, J. Pihler, G. Stumberger, B. Klopcic, and D. Dolinar, "Artificial Neural Network Applied for Detection of Magnetization Level in the Magnetic Core of a Welding 
Transformer," IEEE Transactions on Magnetics, vol. 46, no. 2, pp. 634-637, 2010, doi: 10.1109/TMAG.2009.2031976.

[73] S. S. M. Ghoneim, I. B. M. Taha, and N. I. Elkalashy, "Integrated ANN-based proactive fault diagnostic scheme for power transformers using dissolved gas analysis," IEEE Transactions on Dielectrics and Electrical Insulation, vol. 23, no. 3, pp. 1838-1845, 2016, doi: 10.1109/TDEI.2016.005301.

[74] A. F. Silva, E. G. Silveira, and R. Alipio, "Artificial Neural Network Applied to Differential Protection of Power Transformers," Journal of Control, Automation and Electrical Systems, Nov. 2021, doi: 10.1007/s40313-021-00845-3.

[75] Z. E. Gketsis, M. E. Zervakis, and G. Stavrakakis, "Detection and classification of winding faults in windmill generators using Wavelet Transform and ANN," Electric Power Systems Research, vol. 79, no. 11, pp. 1483-1494, Nov. 2009, doi: https://doi.org/10.1016/i.epsr.2009.05.001.

[76] Z. A. Barakat, A. A. Hajjar, T. Kherbek, and H. H. Alhelou, "Discriminating Between Loss of Excitation and Power Swings in Synchronous Generator Based on ANN," Journal of Control, Automation and Electrical Systems, vol. 4, pp. 545-556, 2019.

[77] J. Upendar, C. P. Gupta, G. K. Singh, and G. Ramakrishna, "PSO and ANN-based fault classification for protective relaying," IET Generation, Transmission \& Distribution, vol. 4, no. 10, pp. 1197 - 1212, 2010, doi: 10.1049/iet-gtd.2009.0488.

[78] H. Fathabadi, "Novel filter based ANN approach for short-circuit faults detection, classification and location in power transmission lines," International Journal of Electrical Power \& Energy Systems, vol. 74, pp. 374-383, Jan. 2016, doi: https://doi.org/10.1016/i.ijepes.2015.08.005.

[79] A. Abdullah, "Ultrafast Transmission Line Fault Detection Using a DWT-Based ANN," IEEE Transactions on Industry Applications, vol. 54, no. 2, pp. 1182-1193, 2018, doi: 10.1109/TIA.2017.2774202.

[80] B. Rathore, O. P. Mahela, B. Khan, H. H. Alhelou, and P. Siano, "Wavelet-Alienation-NeuralBased Protection Scheme for STATCOM Compensated Transmission Line," IEEE Transactions on Industrial Informatics, vol. 17, no. 4, pp. 2557-2565, 2021, doi: 10.1109/TII.2020.3001063.

[81] A. S. Bretas, L. Pires, M. Moreto, and R. H. Salim, "A BP Neural Network Based Technique for HIF Detection and Location on Distribution Systems with Distributed Generation," in Computational Intelligence. Berlin, Germany: Springer, 2010.

[82] M. Kalech, "Cyber-attack detection in SCADA systems using temporal pattern recognition techniques," Computers \& Security, vol. 84, pp. 225-238, Jul. 2019, doi: https://doi.org/10.1016/i.cose.2019.03.007.

[83] S. S. Ali and B. J. Choi, "State-of-the-Art Artificial Intelligence Techniques for Distributed Smart Grids: A Review," Electronics, vol. 9, no. 6, p. 1030, 2020. [Online]. Available: https://www.mdpi.com/2079-9292/9/6/1030.

[84] S. Mousavian, J. Valenzuela, and J. Wang, "Real-time data reassurance in electrical power systems based on artificial neural networks," Electric Power Systems Research, vol. 96, pp. 285-295, Mar. 2013, doi: https://doi.org/10.1016/i.epsr.2012.11.015.

[85] Y. Zhang, F. Lin, and K. Wang, "Robustness of Short-Term Wind Power Forecasting against False Data Injection Attacks," Energies, vol. 13, no. 15, p. 3780, 2020. [Online]. Available: https://www.mdpi.com/1996-1073/13/15/3780.

[86] M. Khoshdeli, I. Niazazari, R. J. Hamidi, H. Livani, and B. Parvin, "Electromagnetic transient events (EMTE) classification in transmission grids," in 2017 IEEE Power \& Energy Society General Meeting, 16-20 Jul. 2017, pp. 1-5, doi: 10.1109/PESGM.2017.8273984.

[87] I. Niazazari, R. Jalilzadeh Hamidi, H. Livani, and R. Arghandeh, "Cause identification of electromagnetic transient events using spatiotemporal feature learning," International Journal of Electrical Power \& Energy Systems, vol. 123, p. 106255, Dec. 2020, doi: https://doi.org/10.1016/j.ijepes.2020.106255. 
[88] D. A. Pisner and D. M. Schnyer, "Support vector machine," in Machine Learning Methods and Applications to Brain Disorders. London, UK: Elsevier, 2020, ch. 6, pp. 101-121.

[89] M. Bigdeli, M. Vakilian, and E. Rahimpour, "Transformer winding faults classification based on transfer function analysis by support vector machine," IET Electric Power Applications, vol. 6, no. 5, pp. 268-276. [Online]. Available: https://digitallibrary.theiet.org/content/journals/10.1049/iet-epa.2011.0232

[90] Z. Jiao and Z. Li, "Novel Magnetization Hysteresis-Based Power-Transformer Protection Algorithm," IEEE Transactions on Power Delivery, vol. 33, no. 5, pp. 2562-2570, 2018, doi: 10.1109/TPWRD.2018.2837022.

[91] L. D. Simões, H. J. D. Costa, M. N. O. Aires, R. P. Medeiros, F. B. Costa, and A. S. Bretas, "A power transformer differential protection based on support vector machine and wavelet transform," Electric Power Systems Research, vol. 197, p. 107297, Aug. 2021, doi: https://doi.org/10.1016/i.epsr.2021.107297.

[92] E. Pajuelo, R. Gokaraju, and M. S. Sachdev, "Identification of generator loss-of-excitation from power-swing conditions using a fast pattern classification method," IET Generation, Transmission \&amp; Distribution, vol. 7, no. 1, pp. 24-36. [Online]. Available: https://digitallibrary.theiet.org/content/journals/10.1049/iet-gtd.2012.0340

[93] M. Rasoulpour, T. Amraee, and A. K. Sedigh, "A Relay Logic for Total and Partial Loss of Excitation Protection in Synchronous Generators," IEEE Transactions on Power Delivery, vol. 35, no. 3, pp. 1432-1442, 2020, doi: 10.1109/TPWRD.2019.2945259.

[94] M. El-Saadawi and A. Hatata, "A novel protection scheme for synchronous generator stator windings based on SVM," Protection and Control of Modern Power Systems, vol. 2, no. 1, p. 24, Jul. 2017, doi: 10.1186/s41601-017-0057-x.

[95] M. Jaya Bharata Reddy, P. Gopakumar, and D. K. Mohanta, "A novel transmission line protection using DOST and SVM," Engineering Science and Technology, an International Journal, vol. 19, no. 2, pp. 1027-1039, Jun. 2016, doi: https://doi.org/10.1016/j.jestch.2015.12.011.

[96] R. Muzzammel and A. Raza, "A Support Vector Machine Learning-Based Protection Technique for MT-HVDC Systems," Energies, vol. 13, no. 24, p. 6668, 2020. [Online]. Available: https://www.mdpi.com/1996-1073/13/24/6668.

[97] R. Salat and S. Osowski, "Accurate fault location in the power transmission line using support vector machine approach," IEEE Transactions on Power Systems, vol. 19, no. 2, pp. 979-986, 2004, doi: 10.1109/TPWRS.2004.825883.

[98] P. Janik and T. Lobos, "Automated classification of power-quality disturbances using SVM and RBF networks," IEEE Transactions on Power Delivery, vol. 21, no. 3, pp. 1663-1669, 2006, doi: 10.1109/TPWRD.2006.874114.

[99] B. Ravikumar, D. Thukaram, and H. P. Khincha, "Knowledge-Based Approach Using Support Vector Machine for Transmission Line Distance Relay Co-ordination," (in En), Journal of Electrical Engineering and Technology, vol. 3, no. 3, pp. 363-372, Sep. 2008, doi: 10.5370/JEET.2008.3.3.363.

[100] U. B. Parikh, B. Das, and R. Maheshwari, "Fault classification technique for series compensated transmission line using support vector machine," International Journal of Electrical Power \& Energy Systems, vol. 32, no. 6, pp. 629-636, Jul. 2010, doi: https://doi.org/10.1016/i.ijepes.2009.11.020.

[101] Y. Zhang, L. Wang, W. Sun, I. R. C. Green, and M. Alam, "Distributed Intrusion Detection System in a Multi-Layer Network Architecture of Smart Grids," IEEE Transactions on Smart Grid, vol. 2, no. 4, pp. 796-808, 2011, doi: 10.1109/TSG.2011.2159818.

[102] C. C. Sun, D. J. S. Cardenas, A. Hahn, and C. C. Liu, "Intrusion Detection for Cybersecurity of Smart Meters," IEEE Transactions on Smart Grid, vol. 12, no. 1, pp. 612-622, 2021, doi: 10.1109/TSG.2020.3010230. 
[103] H. Rizwan ul, C. Li, and Y. Liu, "Online dynamic security assessment of wind integrated power system using SDAE with SVM ensemble boosting learner," International Journal of Electrical Power \& Energy Systems, vol. 125, p. 106429, Feb. 2021, doi: https://doi.org/10.1016/i.ijepes.2020.106429.

[104] H. Drucker, W. Donghui, and V. N. Vapnik, "Support vector machines for spam categorization," IEEE Transactions on Neural Networks, vol. 10, no. 5, pp. 1048-1054, 1999, doi: 10.1109/72.788645.

[105] D. Bejmert, W. Rebizant, and L. Schiel, "Transformer differential protection with fuzzy logic based inrush stabilization," International Journal of Electrical Power \& Energy Systems, vol. 63, pp. 51-63, Dec. 2014, doi: https://doi.org/10.1016/j.ijepes.2014.05.056.

[106] D. Granados-Lieberman, J. R. Razo-Hernandez, V. Venegas-Rebollar, J. C. Olivares-Galvan, and M. Valtierra-Rodriguez, "Harmonic PMU and Fuzzy Logic for Online Detection of ShortCircuited Turns in Transformers," Electric Power Systems Research, vol. 190, p. 106862, Jan. 2021, doi: https://doi.org/10.1016/i.epsr.2020.106862.

[107] H. Eristi, "Fault diagnosis system for series compensated transmission line based on wavelet transform and adaptive neuro-fuzzy inference system," Measurement, vol. 46, no. 1, pp. 393-401, Jan. 2013, doi: https://doi.org/10.1016/i.measurement.2012.07.014.

[108] R. K. Goli, A. Gafoor Shaik, and S. S. Tulasi Ram, "A transient current based double line transmission system protection using fuzzy-wavelet approach in the presence of UPFC," International Journal of Electrical Power \& Energy Systems, vol. 70, pp. 91-98, Sep. 2015, doi: https://doi.org/10.1016/j.ijepes.2015.01.024. 